\title{
TANZANIA Mainland Poverty
} Assessment

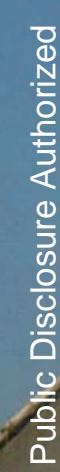

EXECUTIVESUMMARY

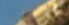

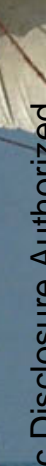

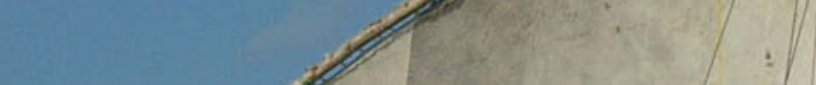

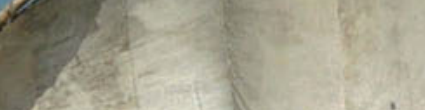

0
0
0
5
$\frac{1}{1}$
0
$\frac{1}{5}$
0
0
0
0
0
0
0

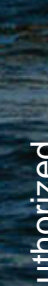

(4) WORLD BANKGROUP 


\section{Standard Disclaimer:}

This volume is a product of the staff of the International Bank for Reconstruction and Development/ The World Bank. The findings, interpretations, and conclusions expressed in this paper do not necessarily reflect the views of the Executive Directors of The World Bank or the governments they represent. The World Bank does not guarantee the accuracy of the data included in this work. The boundaries, colors, denominations, and other information shown on any map in this work do not imply any judgment on the part of The World Bank concerning the legal status of any territory or the endorsement or acceptance of such boundaries.

\section{Copyright Statement:}

The material in this publication is copyrighted. Copying and/or transmitting portions or all of this work without permission may be a violation of applicable law. The International Bank for Reconstruction and Development/ The World Bank encourages dissemination of its work and will normally grant permission to reproduce portions of the work promptly.

For permission to photocopy or reprint any part of this work, please send a request with complete information to the Copyright Clearance Center, Inc., 222 Rosewood Drive, Danvers, MA 01923, USA, telephone 978-750-8400, fax 978-750-4470, http://www.copyright.com/.

All other queries on rights and licenses, including subsidiary rights, should be addressed to the Office of the Publisher, The World Bank, 1818 H Street NW, Washington, DC 20433, USA, fax 202-522-2422, e-mail pubrights@worldbank.org. 


\section{Acknowledgments}

- he Poverty Assessment for Mainland Tanzania was prepared by Nadia Belhaj Hassine Belghith, Wendy Karamba, Elizabeth Talbert, and Pierre de Boisseson. We are grateful for the invaluable contributions of David Newhouse, Takaaki Masaki, Arden Finn, Marco Ranzani, Sasun Tsirunyan, Jia Jun Lee, Foluyinka Fakoya, David Garcés Urzainqui, Ingela Alger, Kristen Himelein, Jonathan Kastelic, Diana Winter, Christiane Wissa, Andre Marie Taptue, and Freeha Fatima.

The report was prepared in close collaboration with the Ministry of Finance and Planning and the National Bureau of Statistics of the United Republic of Tanzania. We express our sincere thanks to Dr. Albina Chuwa, Sylvia Meku, and the Household Budget Survey team from the National Bureau of Statistics for the important support and critical feedback provided throughout the preparation of the report and for facilitating the exchanges.

The report benefited from several consultations and insights from groups of stakeholders, including senior officials from the Ministry of Finance, the Office of the Prime Minister, Tanzania Social Action Fund, REPOA, and development partners.

The report also benefited from comments and advice from Yutaka Yoshino, Nobuo Yoshida, Tomomi Tanaka, and Mohamed Ihsan Ajwad. The team gratefully acknowledges guidance from Bella Bird, Preeti Arora, and Pierella Paci.

The team offers its thanks to Loy Nabeta, Elizabeth Howton, and Anne Grant for their precious help during the editing and communication process. The team also extends its thanks to Martin Buchara, Arlette Sourou, Tsehaynesh Michael Seltan, Santosh Kumar Sahoo, Diana Mpoki Mwaipopo, and Anila Jane Mohan for their invaluable assistance during the preparation of the report. 


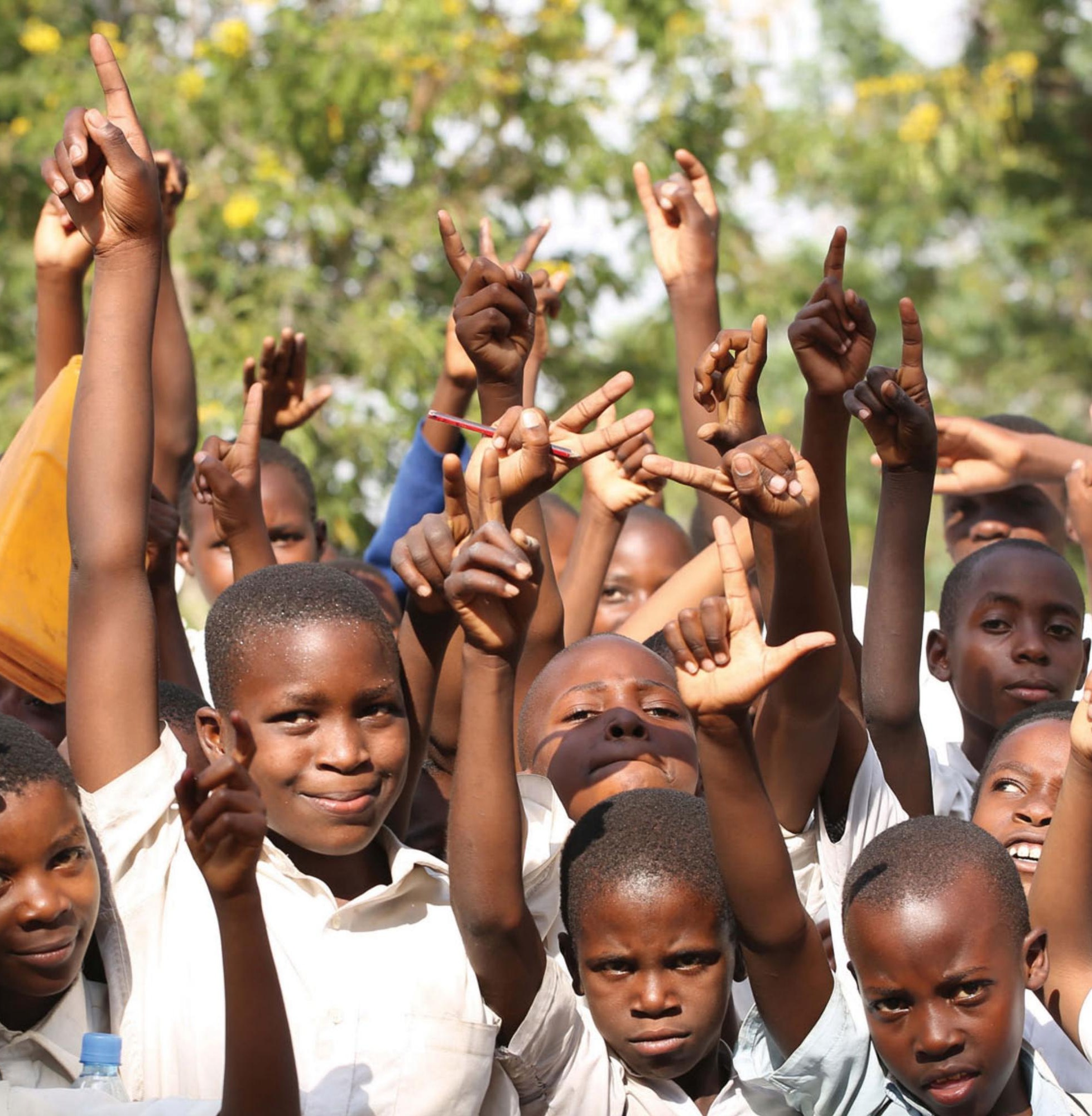




\section{Overview}

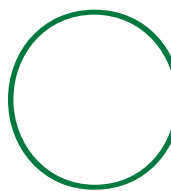

ver the past decade Tanzania recorded remarkable economic growth and a persistent decline

in poverty. The country's strategic location, its rich and diverse resources, its sociopolitical stability, and its economic reforms over the past four decades contributed to its economic success and serve as a foundation for further building up the economy. Continued government efforts to improve living conditions have resulted in a sustained increase in access to basic services and improvement in human capital outcomes (though from a low base), which helped to reduce poverty. After plateauing between 2001 and 2007, in 2018 the poverty rate fell from 34.4 to 26.4 percent.

However, Tanzania's success is not unmitigated. Poverty was not reduced as much as the population grew, resulting in an increase in the absolute number of poor people. In 2018, about 14 million people lived below the national poverty line of TZS 49,320 per adult equivalent per month and about 26 million (about 49 percent of the population) lived below the $\$ 1.90$ per person per day international poverty line. Vulnerability is also still high: for every four Tanzanians who moved out of poverty, three fell into it. A large number of nonpoor people living just above the poverty line are at risk of slipping below it. Beyond the persistent gaps between urban and rural areas, there are large disparities in the distribution of poverty across geographic regions. Poverty is highly concentrated in the western and lake zones, and lowest in the eastern zones.

The reduction in poverty is also low in relation to Tanzania's remarkable economic growth. The growth elasticity of poverty indicates that a 10 percent increase in Gross Domestic Product (GDP) growth per capita in Tanzania can be expected to reduce the proportion of the poor by about 4.5 percent-low compared to estimates for other developing countries. This is due to both the concentration of employment in slow-growing sectors and the dilatory transformation of the economy. Based on national accounts data, industry and services are growing much faster than agriculture, driving the growth and transformation of the economy. However, the fastest growing subsectors each employ on average no more than 3 percent of the general population. They also tend to employ significantly more educated Tanzanians; their workers who have completed secondary and above exceed 60 percent on average. Data from household surveys indicate a transition of labor from low productive agriculture to higher productive 
industry and services, but the transition is significantly slower than the transformation suggested by national accounts data. Lack of education and productive resources hold people back from improving their economic standing by moving to more productive sectors. Only those equipped with more human capital and assets are able to benefit from the opportunities generated by economic growth; they increase their incomes and consumption much faster than the rest of the population. The result is more inequality. This pattern is partly driven by intergenerational transmission of poverty: low parental education and economic status constrain the employment of their children, limit their upward mobility, and slow structural transformation. This contributes to perpetuate poverty and inequality across generations and deters efforts to eradicate poverty.

\section{This report summarizes a comprehensive analysis of poverty and inequality in Tanzania and identifies some} priority actions if poverty is to be reduced. The first part is based on the results of the Household Budget Surveys (HBSs) for 2007, 2012, and 2018; several rounds of National Panel Surveys (NPSs); and Demographic Health Survey (DHS) data. It also combines spatial information from the population census and other sources with HBS data to (1) provide a rigorous analysis of the evolution, profile, and determinants of poverty and inequality; (2) explore movements in and out of poverty and their drivers; and (3) examine the distribution of poverty and living conditions across the country at a detailed geographic level. The second and final part examines the pattern of structural transformation, firm profiles, job creation, and financial inclusion using the rebased GDP figures released in February 2019, plus data from the Statistical Business Register (SBR), Census of Industrial Production (CIP), national accounts, NPS, Integrated Labor Force Surveys (ILFS), and other sources. This executive summary provides an overview of all the findings; The full report will be available on the World Bank website starting from January 2020: http:// openknowledge.www.worldbank.org/. 


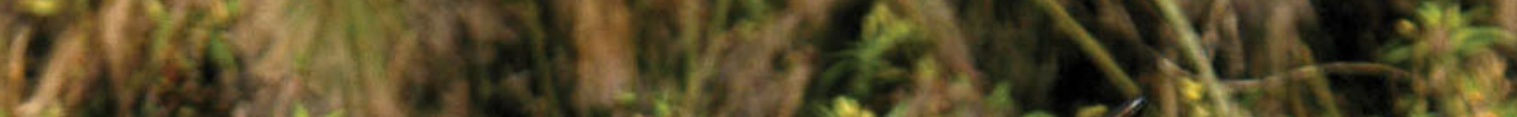

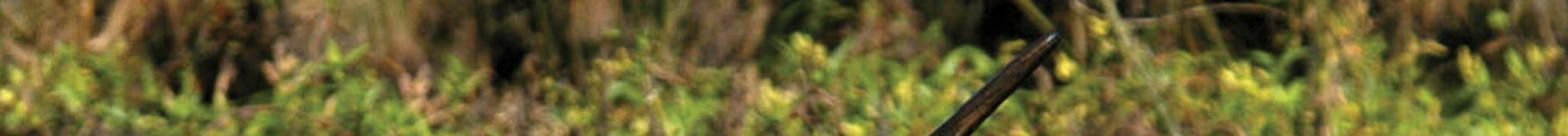

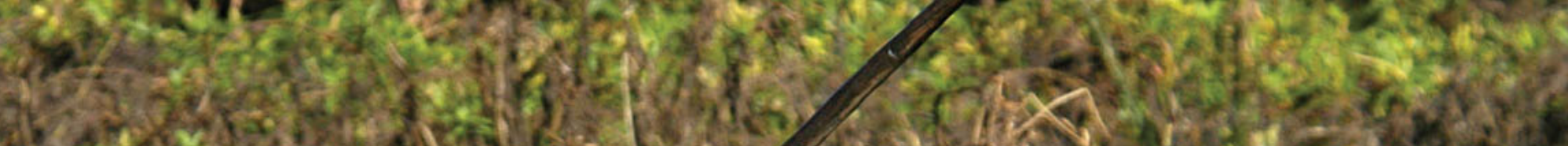

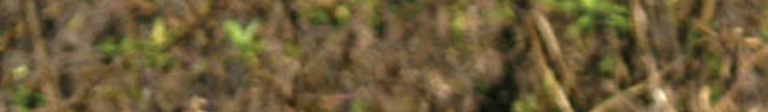

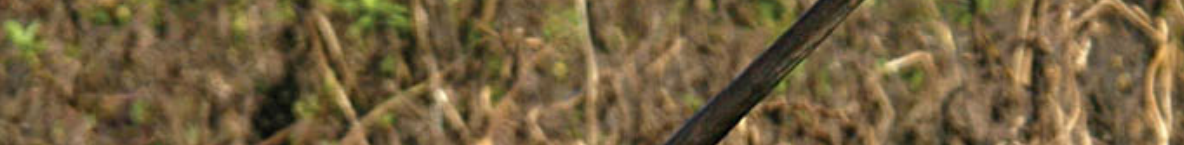

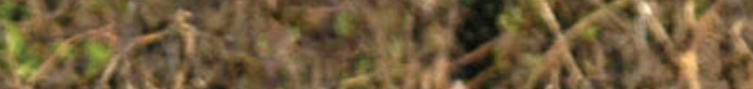

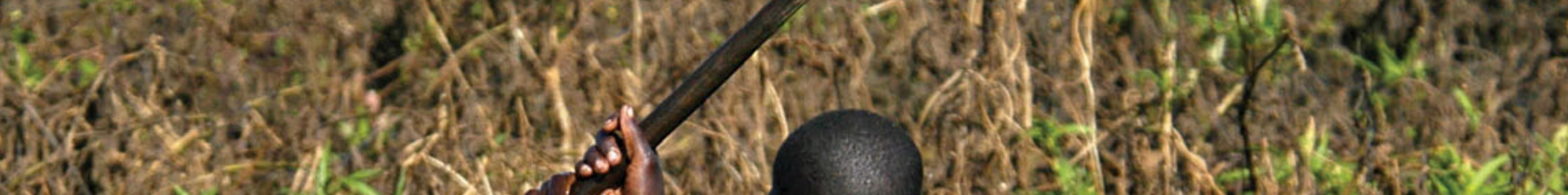

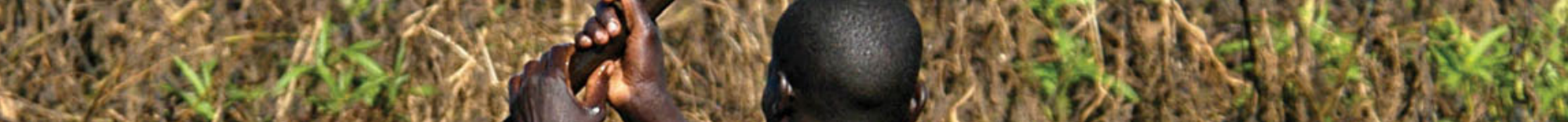

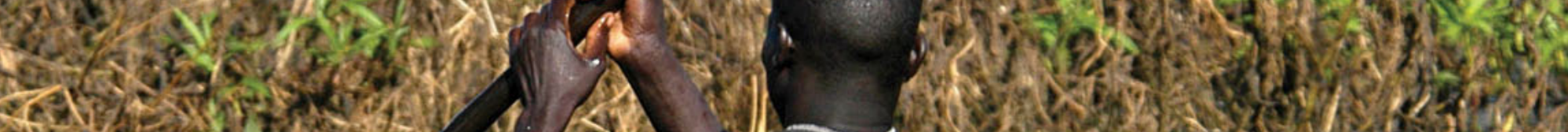
5.

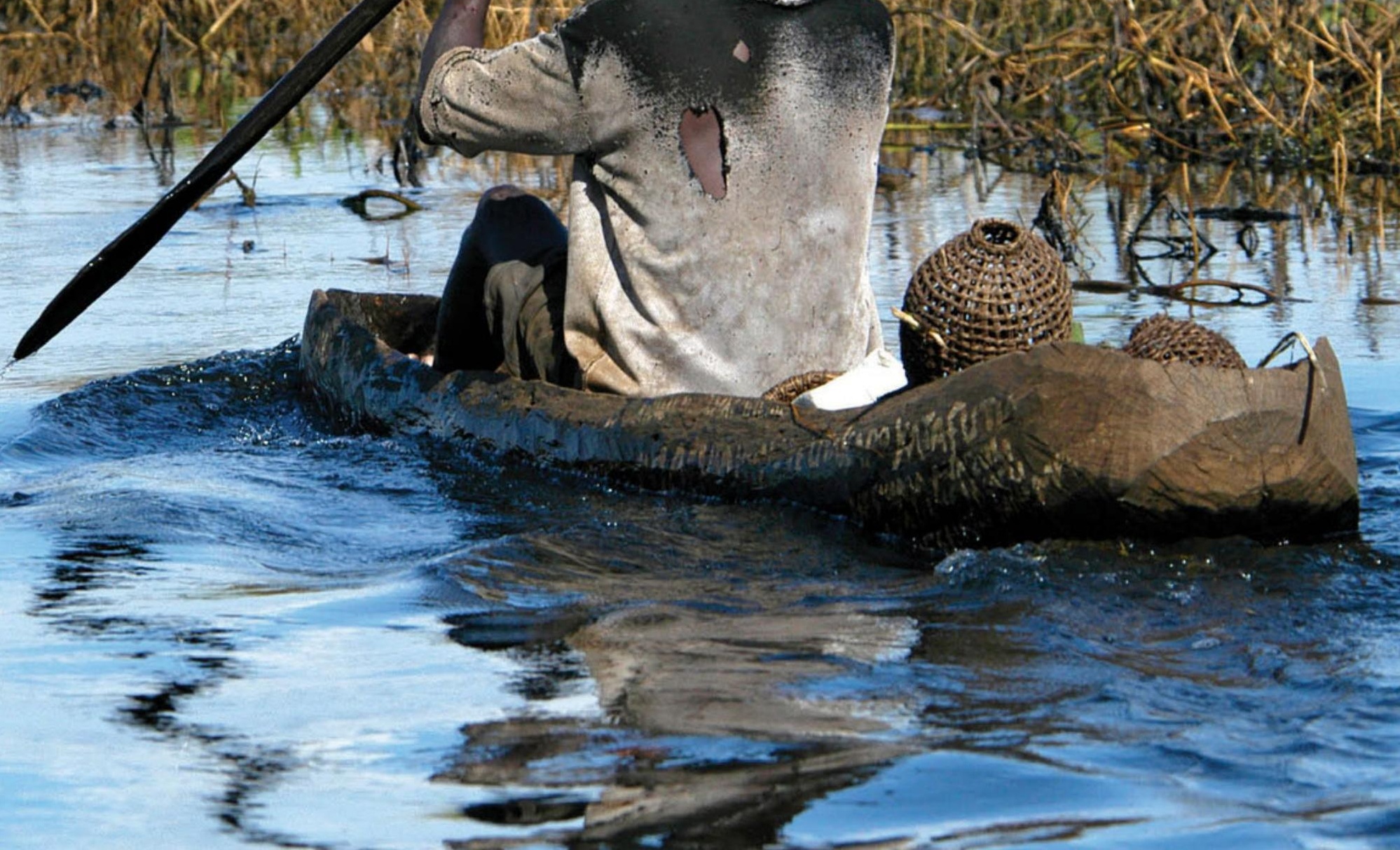




\section{Poverty Has Been Falling for a Decade, but Recently the Pace Has Slowed}

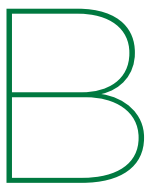

etween 2007 and 2018 Tanzania's national poverty rate fell from 34.4 to 26.4 percent, and extreme poverty fell from 12 to 8 percent. The figures on poverty trends are drawn from the results of the Household Budget Surveys (HBS) for 2007, 2011/12, and 2017/18. The poor are defined as those whose consumption is below the national poverty line and who therefore were not able to meet their basic consumption needs; the extreme poor were not able to afford enough food to meet the minimum nutritional requirements of 2,200 kilocalories (Kcal) per adult per day. The national basic needs poverty line for 2018 was TZS 49,320 per adult per month and the food

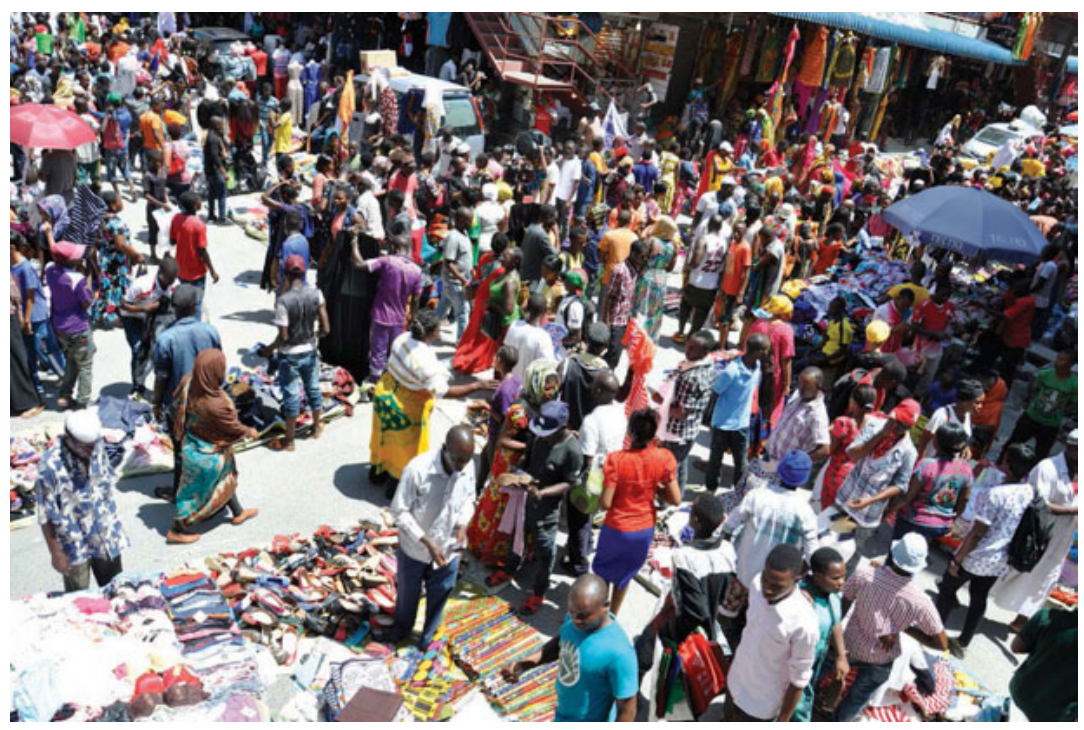
poverty line was TZS 33,748. Poverty fell across the board but faster in rural areas, where poverty fell from 39.1 to 33.1 percent, compared to a decline from 20.0 to 15.8 percent in urban areas (Figure ES.1). Extreme poverty went down from 13.3 to 9.7 percent in rural areas and from 7.4 to 4.4 percent in urban areas.

\section{Poverty declined faster between} 2007 and 2012 than it has since. For 2007-12, poverty averaged a decline of 1 percentage point (pp) a year, but the total reduction since has been from 


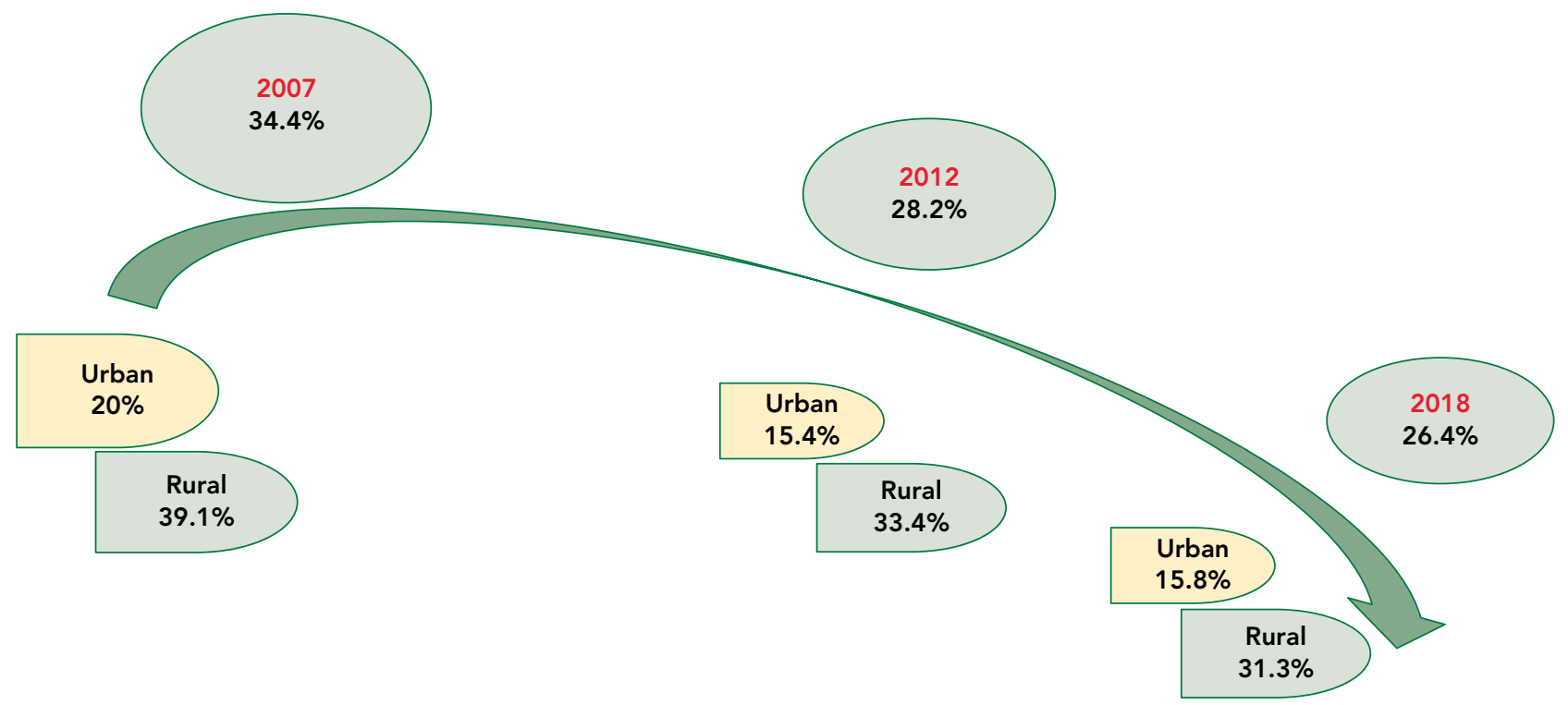

Source: HBS 2007, 2011/12, and 2017/18.

28.2 to 26.4 percent. In rural areas, between 2012 and 2018 poverty eased from 33.4 to 31.3 percent, while urban poverty stagnated at around 16 percent.

Poverty in urban areas outside Dar es Salaam did not really begin to fall until 2012. The reduction in urban poverty between 2007 and 2012 was driven entirely by a plunge in the proportion of poor people in Dar es Salaam, from 14 to 4 percent; in other urban areas the drop was marginal, from 22.7 to 21.5 percent. In contrast, between 2012 and 2018, urban areas outside the metropolitan city saw poverty fall to 19.2 percent, while in Dar es Salaam it rose to 8 percent. However, this increase is questionable: it may be driven by changes in the sampling method as survey-to-survey imputation results indicate a decline in poverty from 14 to 8 percent in 2007-12 and stagnation since then.

The depth and severity of poverty also eased. For 2007-18, the depth of poverty, which measures how far on average poor households are from the poverty line, decreased from 10 to 6 percent-in other words, a poor household would on average need TZS 3,058 per adult equivalent per month to escape poverty. Since poverty is deeper 


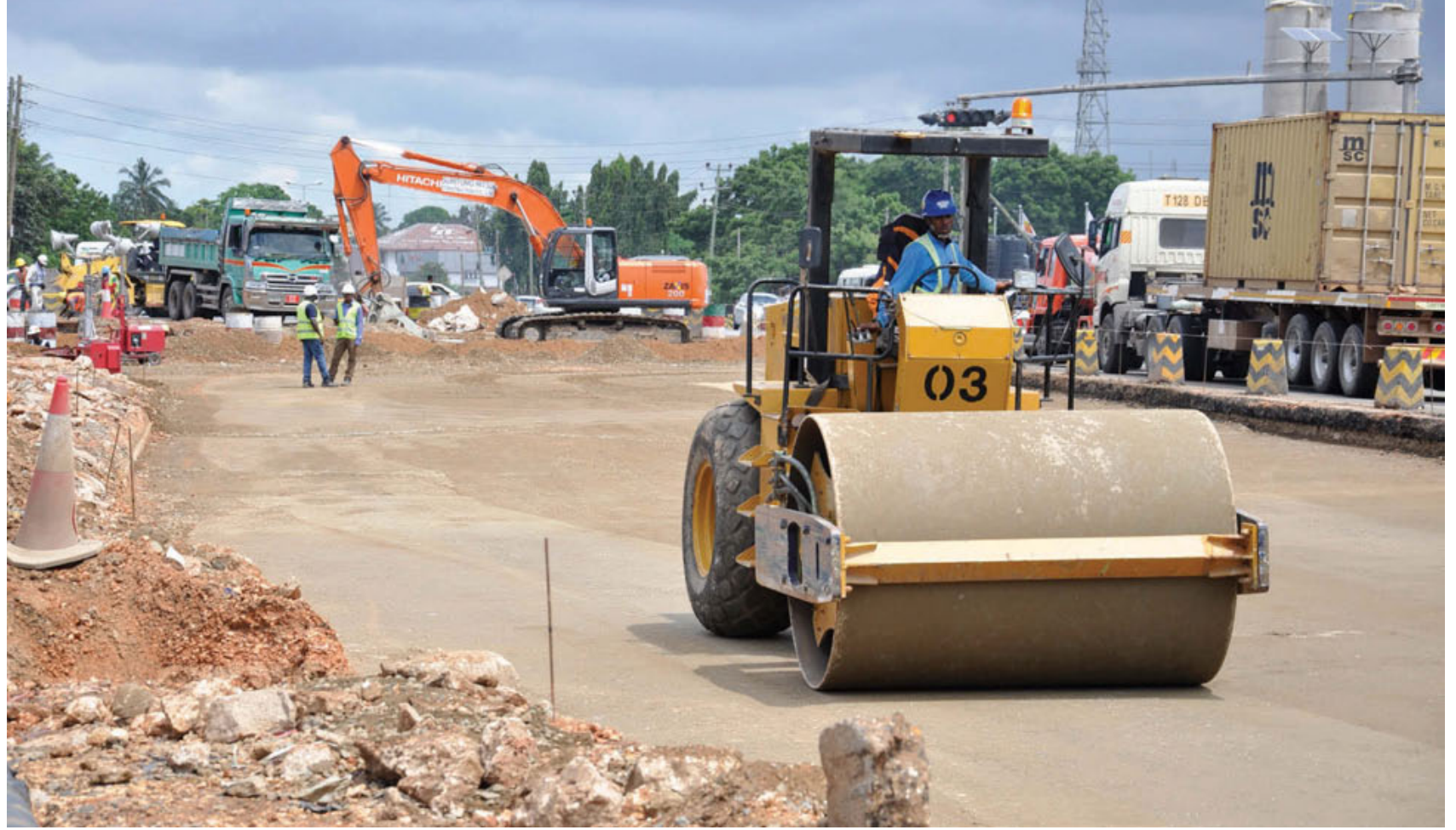

in rural areas, the amount needed there is TZS 3,650, far more than the TZS 1,726 per adult equivalent per month for poor households in urban areas. The low poverty severity index which was more than halved, from 4.5 in 2007 to 2.1 in 2018, suggests that inequality between poor households is fairly low.

The robust record of poverty reduction is not affected by changes in survey methodology. Assessing the changes in poverty over time is subject to issues of comparability stemming from changes in survey design. The 2017/18 HBS introduced computer-assisted personal interviews (CAPI), lessened the length of the diary from 28 to 14 days, and redesigned the sample for regional representation. Analysis and robustness checks, using survey-to-survey imputation methods, showed that the new survey design had little impact on changes in poverty levels and that Tanzania's record of poverty reduction is solid. 


\section{Gradual Improvement in Living Conditions and Human Capital Helped Reduce Poverty}

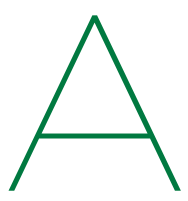

ccess to electricity has progressed somewhat, but electrification of the whole country is still insufficient, particularly in rural areas and for poor households. Although 29 percent of Tanzania's households have access to electricity, access is available to just 10 percent of rural and 7 percent of poor households (Figure ES.2). The country's strategy to diversify toward solar energy has started to pay off, particularly in rural areas, where 33 percent of households use solar energy

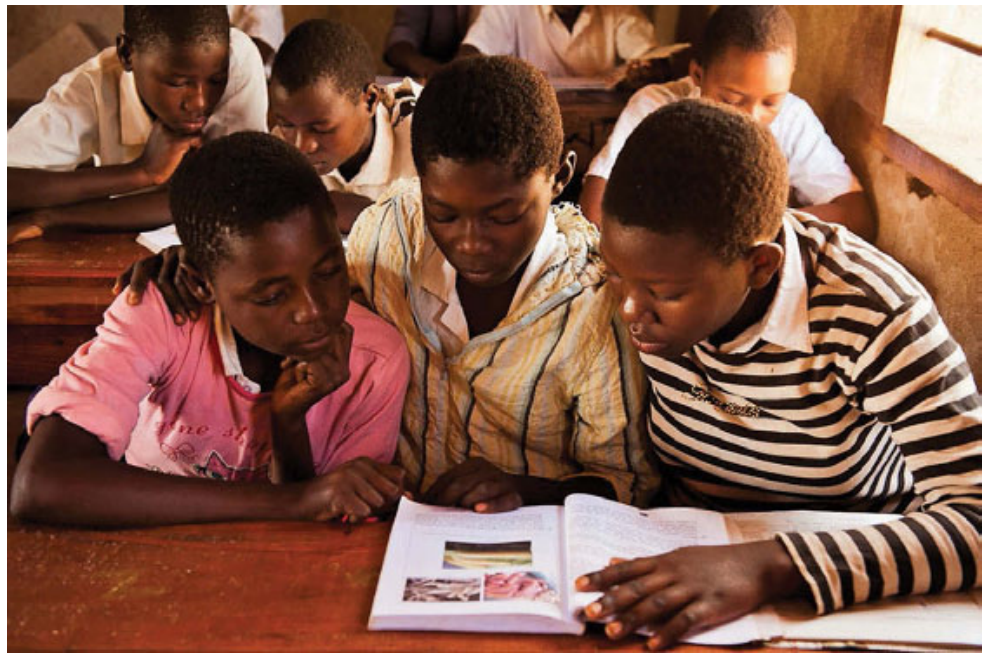
for lighting compared to 14 percent in urban areas. Despite some improvements, about 45 percent of households still rely on such inefficient lighting sources as torches and kerosene. Use of efficient energy sources for cooking has also improved slightly, but over 80 percent of all households, and more than 90 percent of rural and poor households, continue to rely on firewood and charcoal.

More Tanzanians now have safe drinking water, particularly in urban areas, where the percentage of households 
FIGURE ES.2 Source of Lighting, Percent

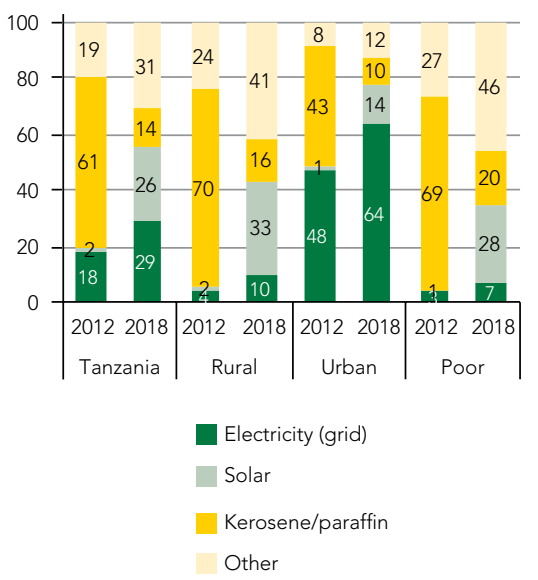

Source: HBS 2011/12 and 2017/18.
FIGURE ES.3 Access to Water,

\section{Percent}

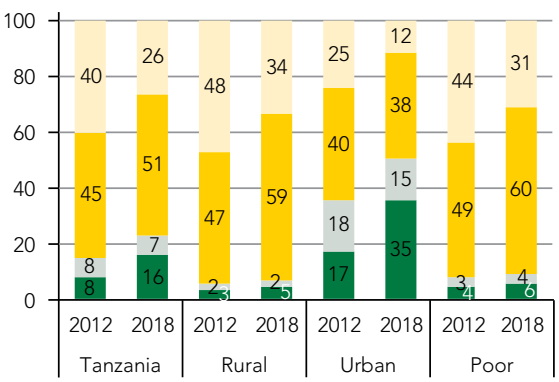

$$
\begin{aligned}
& \text { Piped water inside dwelling } \\
& \text { Piped water outside dwelling } \\
& \text { Improved drinking water } \\
& \text { Unimproved drinking water }
\end{aligned}
$$

Source: HBS 2011/12 and 2017/18.

Note: Using WHO definitions, improved water includes public tap, protected dug well. Unimproved water includes unprotected sources and surface water.
FIGURE ES.4 Access to

Sanitation, Percent

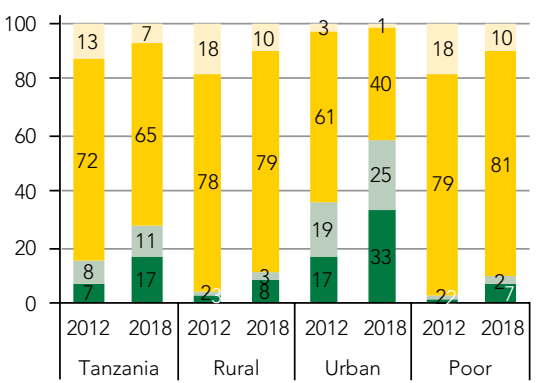

Basic sanitation

Limited sanitation

Unimproved sanitation

Open defecation

Source: HBS 2011/12 and 2017/18.

Note: Using SDG definitions, basic sanitation includes non-shared flush toilets or improved pit latrines. Limited sanitation includes shared flush toilets or improved pit latrines.

with improved water sources has almost doubled. Piped water systems and household connections to them (mainly urban) contributed to the improvement (Figure ES.3). Water systems also helped to raise the percentage of households with access to piped water, in or outside the dwelling, which has greatly reduced the time and distance needed to access water. However, many households still lack access to a safe source of drinking water. In 2018, the drinking water of about 26 percent of households was unimproved and unsafe_for urban households the rate was 12 percent and for rural 34 percent.

Access to basic and limited sanitation improved considerably in urban areas but is still highly problematic in rural areas. Between 2012 and 2018 the percentage of urban households with improved sanitation rose from 36 to 58 percent, but in rural areas from just 5 percent to a still low 11 percent (Figure ES.4). In 2018, 65 percent of Tanzanian households used unimproved sanitation systems; in rural areas 10 percent of households still mainly use open defecation.

Better access to roads, markets, and public transportation also helped account for the rise in household living standards. Access to roads, public transportation, and markets improved throughout the country, but especially in 
rural areas and for poorer households. Access to cell phone signals, health centers, and to a lesser extent banks also expanded among the poor, especially in urban areas other than Dar es Salaam. However, improvements were from the low base and are still far from sufficient.

As ownership of modern assets has risen, ownership of traditional goods has declined. More Tanzanian households now have mobile phones, televisions, motorcycles, refrigerators, and to a lesser extent cars and laptops. Fewer now own more traditional items like radio sets or stoves.

Human development outcomes, particularly in education, are also better. Gross and net enrollment rates in primary schools went up slightly between 2012 and 2018 in both rural and urban areas. However, gross enrollment in both lower and upper secondary decreased, and net enrollment increased only marginally. The combination of stagnant or decreasing gross enrollment with increasing net enrollment does, however, suggest improvements in enrollment within the qualifying age categories and in fewer students repeating classes. Yet in 2018 the lower secondary enrollment rate was only 34 percent, and upper secondary enrollment barely reached 2 percent (Figure ES.5). While more adults aged 15 and older are now attaining lower secondary, the rate is still just 17 percent; the education profile has improved mostly for the younger generation (Figure ES.6). Overall, primary and lower

\section{FIGURE ES.5 Net Education Enrollment Rates 2012-18, Percent}

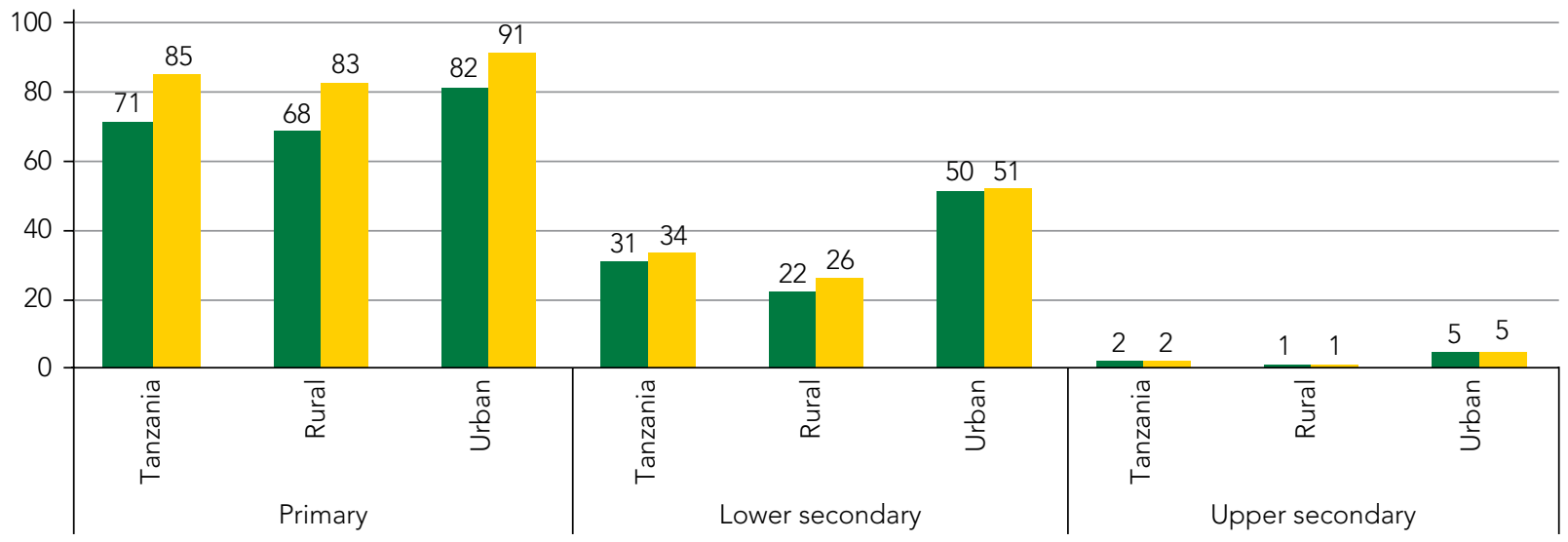

$2012 \square 2018$

Source: HBS 2011/12 and 2017/18. 
secondary education increased for the poor in both urban and rural areas, but enrollments in upper-secondary and university education were significantly larger among the richest urban households. Increased education for women seems to have helped to slightly reduce the total fertility rate. Adult mortality and the probability of dying before age 50 have also fallen.

\section{Despite these improvements,} achievements in human capital are

low. Tanzania was ranked 128th out of 157 countries in the 2018 World Bank Human Capital Project with a low Human Capital Index $(\mathrm{HCl})$ score of 0.4. Low expected years of schooling is among the main limiting factors to the $\mathrm{HCl}$. The World Economic Forum Global Human Capital Report of 2017 also ranked Tanzania 106th of 130 countries in $\mathrm{HCl}$. Tanzania trails countries with similar income levels, underperforming particularly in the know-how subindex (109th) due to the very low share of high-skilled employment, limited availability of skilled employees, and low economic complexity (Figure ES.7).
FIGURE ES.6 Educational Achievements of Adults 15+, 2018, Percent

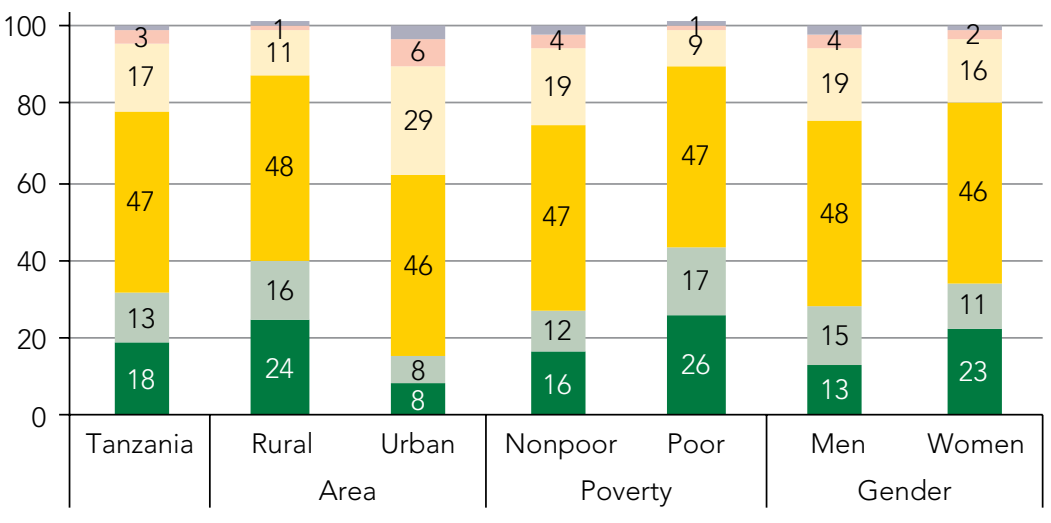

No education Lower secondary

Less than primary
Upper secondary

Completed primary

University

\section{FIGURE ES.7 Human Capital Index}

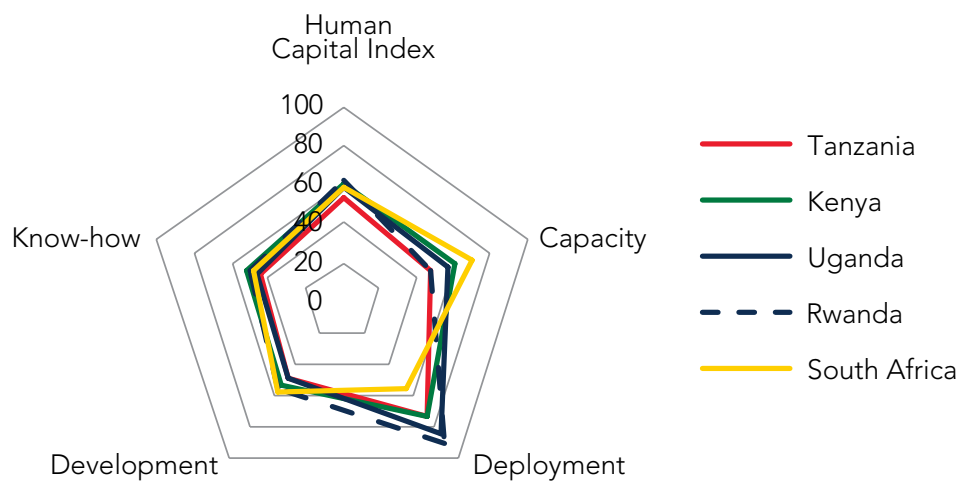

Source: Human Capital Report, 2017.

Over the last decade anthropometric indicators for children under five got better, but undernutrition is still chronic, especially in rural areas. According to the 2015/16 DHS, almost 35 percent of Tanzanian children under 5 

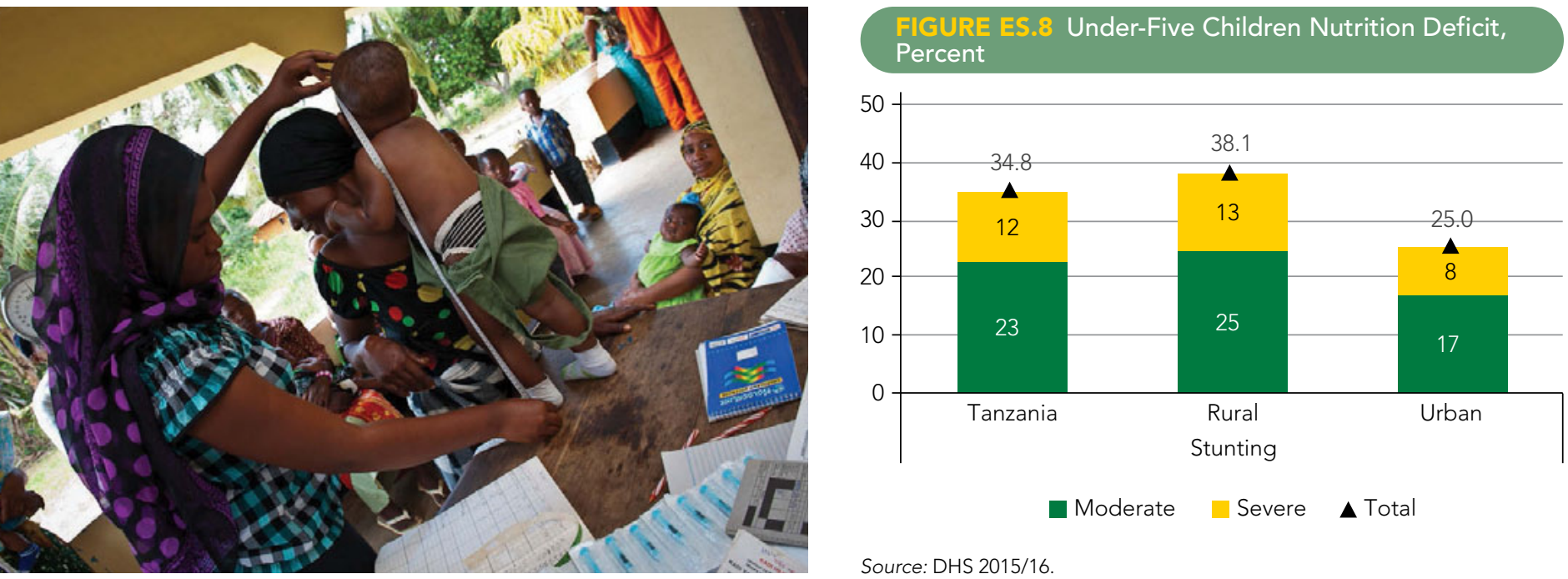

Moderate Severe $\boldsymbol{\Delta}$ Total

Source: DHS 2015/16.

are stunted and 12 percent are severely stunted, indicating a cumulative growth deficit. The problem is particularly acute in rural areas, where about 38 percent of under-five children are stunted (Figure ES.8).

There has been a progressive shift to more productive work in services and industry, but the shift has mostly occurred in urban areas, and among better-off groups. Movement out of agriculture seems to have accelerated since 2012, coupled with more jobs and higher earnings, especially in services and to a lesser extent industry (Figure ES.9). Self-employment also increased. However, these positive changes occurred primarily among households in urban areas that were only moderately poor or already better-off. Poor rural households saw only a slight increase in engagement in self-employment and, while remaining positive, their returns declined over recent years (Figure ES.10). Poor urban households outside Dar es Salaam saw a slight increase in wage employment and in private businesses, coupled with a modest improvement in returns. In general, better-off households, which have more education and other assets, were better positioned to take advantage of the opportunities generated by economic growth and so were able to raise their consumption much faster than poor households.

These improvements helped to raise household consumption, but the benefits were partly offset by the lack of opportunities for meaningfully higher economic returns. The reduction in poverty was driven by better access to basic services, assets, and infrastructure; and more human capital, which helped to raise both household endowments and living standards. However, these endowments no longer generate the same increase in consumption 


\section{FIGURE ES.9 Drivers of Poverty Reduction in Mainland Tanzania, 2012-18: Endowments and Returns Effects, Percent}

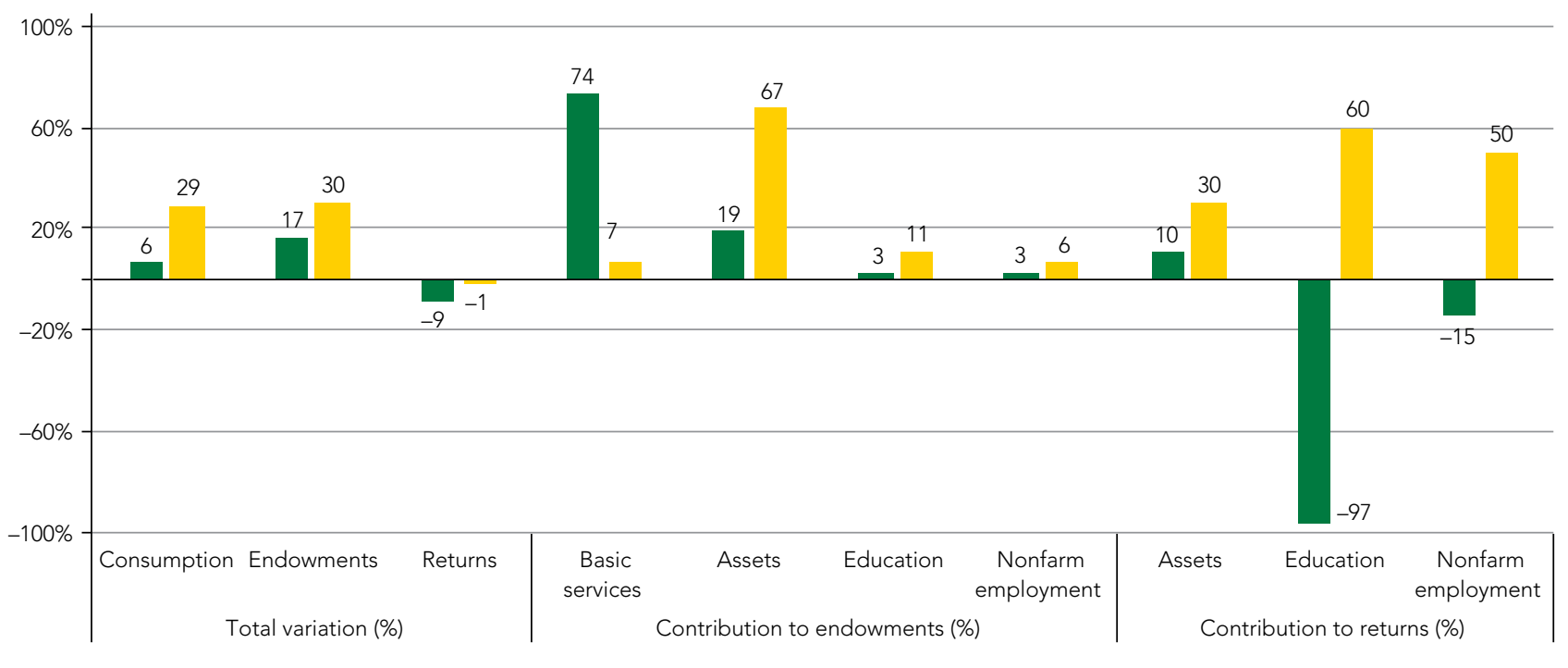

Poor Better-off

Source: HBS 2011/12 and 2017/18

Note:

- Results are based on the unconditional quantile regression, which decomposes changes in consumption over time into changes in people characteristics or endowments (i.e., increased education levels, ownership of assets, and access to productive employment) and the returns that they get for those endowments (i.e., returns to education, employment, and assets). The method applies the Oaxaca-Blinder decomposition to each unconditional decile of the consumption distribution to assess the amount of poverty reduction attributable to changes in the endowments of households and the amount due to changes in the returns to these endowments.

- The poor are those in the first three deciles, and the better-off are those in the two highest deciles.

- Nonfarm employment groups self-employment as well as employment in services and industry. Improvements among the poor are due to higher engagement in self-employment alone, while improvements among the better-off are due to higher engagement in self-employment with others, as well as better access (and higher returns) to wage employment and employment in industry and services.

as previously, so that the reduction in poverty was slower than what would have been achieved previously. The expansion of access to education and the increase in educational attainment in the general population has paralleled changes in labor market requirements, so that the rewards for years of schooling below a certain level have declined. In particular, the gains in income and consumption associated with primary education have become minimal. Consequently, poorer households, whose heads are generally older and cannot access more education, have seen a marked decline in the returns to their years of schooling. As more people have mobile phones and access 


\section{FIGURE ES.10 Drivers of Poverty Reduction in Rural Areas, 2012-18, Percent}

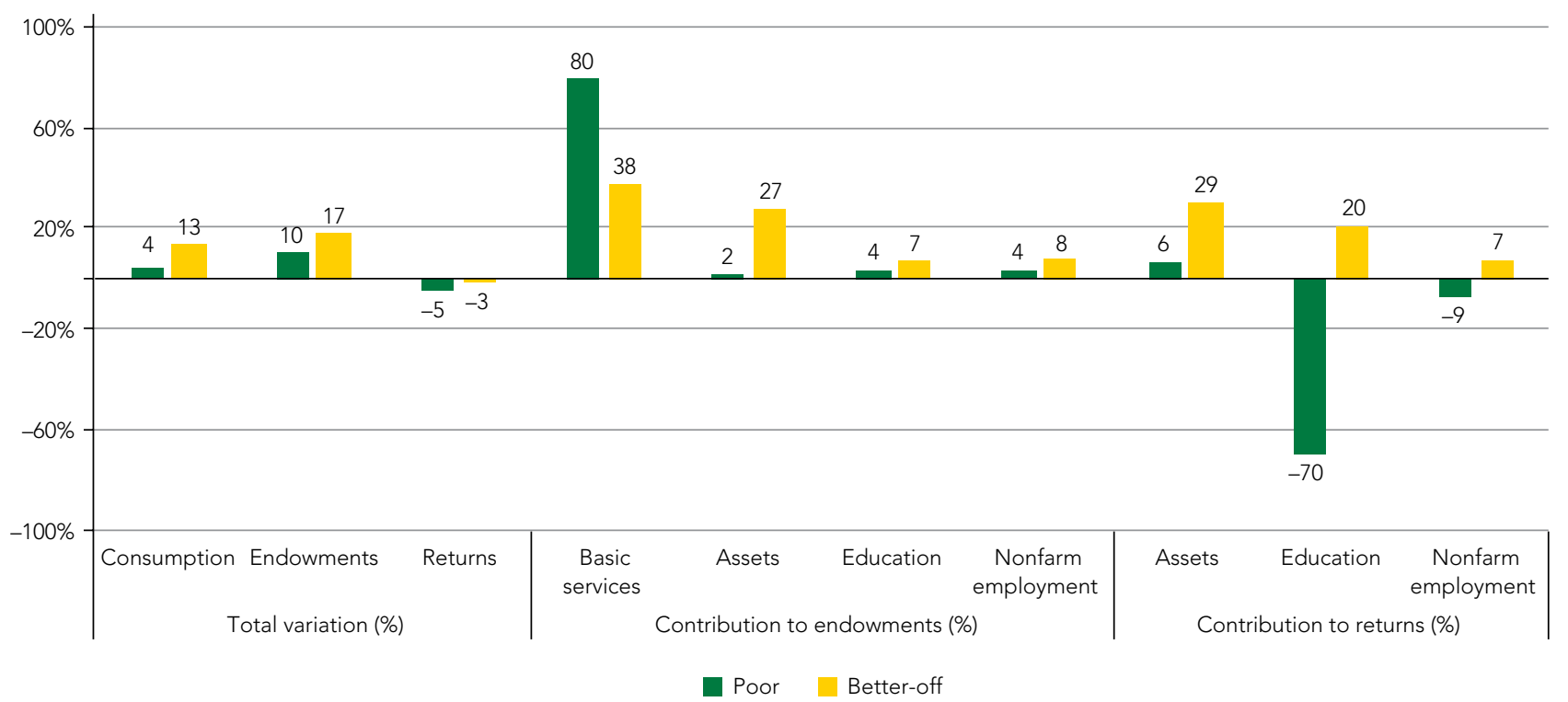

Source: HBS 2011/12 and 2017/18.

to mobile signals and the Internet, the value that such devices add to consumption lessens. Popular for business purposes and fund transfers, mobile phones continue to positively affect the livelihoods of the poor. However, since 2012 their marginal benefits have narrowed, especially in urban areas and in moderately poor households, for whom ownership of these assets has expanded rapidly but opportunities for their productive use have not (Figure ES.11). Similarly, returns from greater market access have been falling, especially in rural areas. Possession of modern transportation assets like motorcycles and cars has significantly reduced the returns to bicycles and other basic transport alternatives, which are still quite prevalent among the poor. 
FIGURE ES.11 Drivers of Poverty Reduction in Urban Areas, 2012-18, Percent

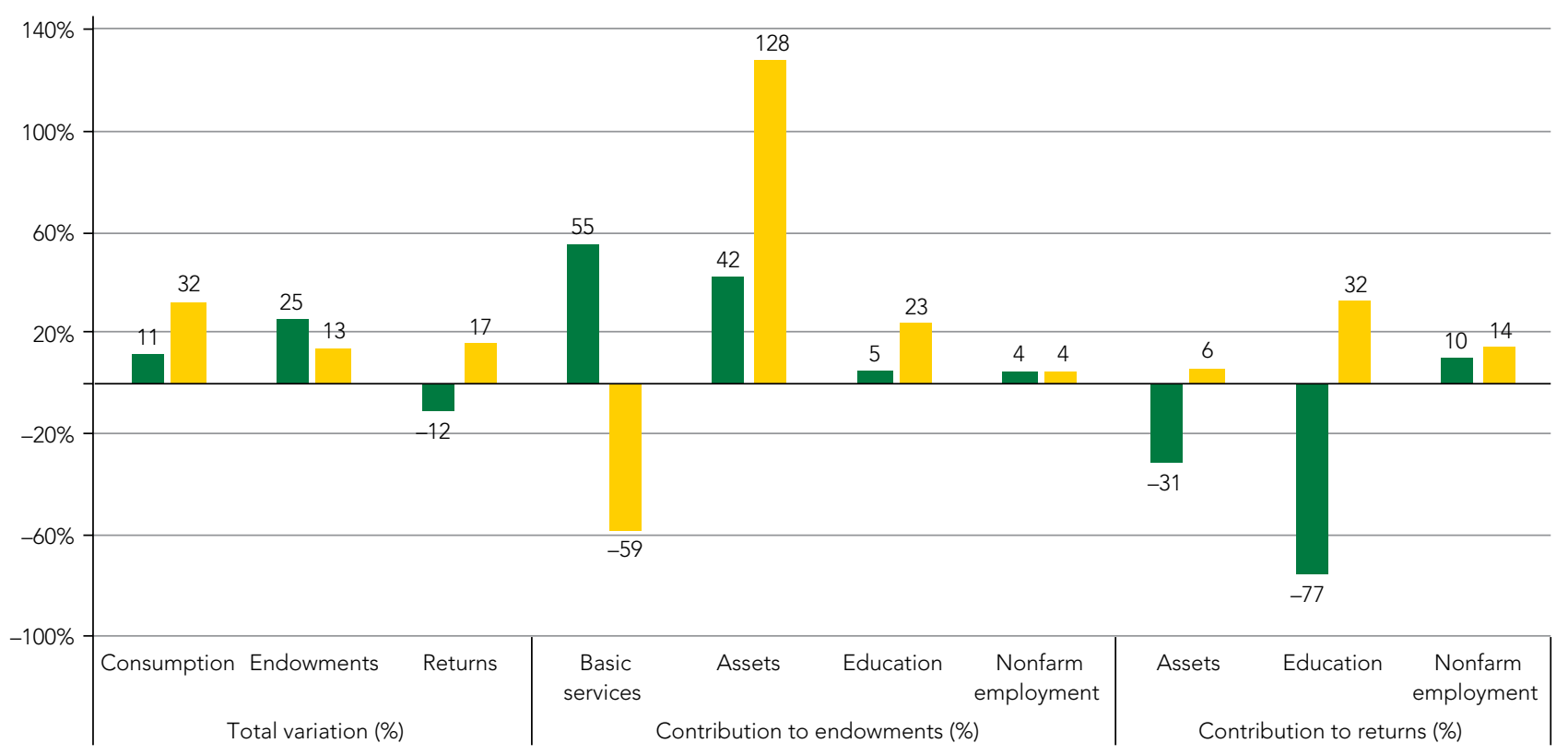

Poor Better-off

Source: HBS 2011/12 and 2017/18.

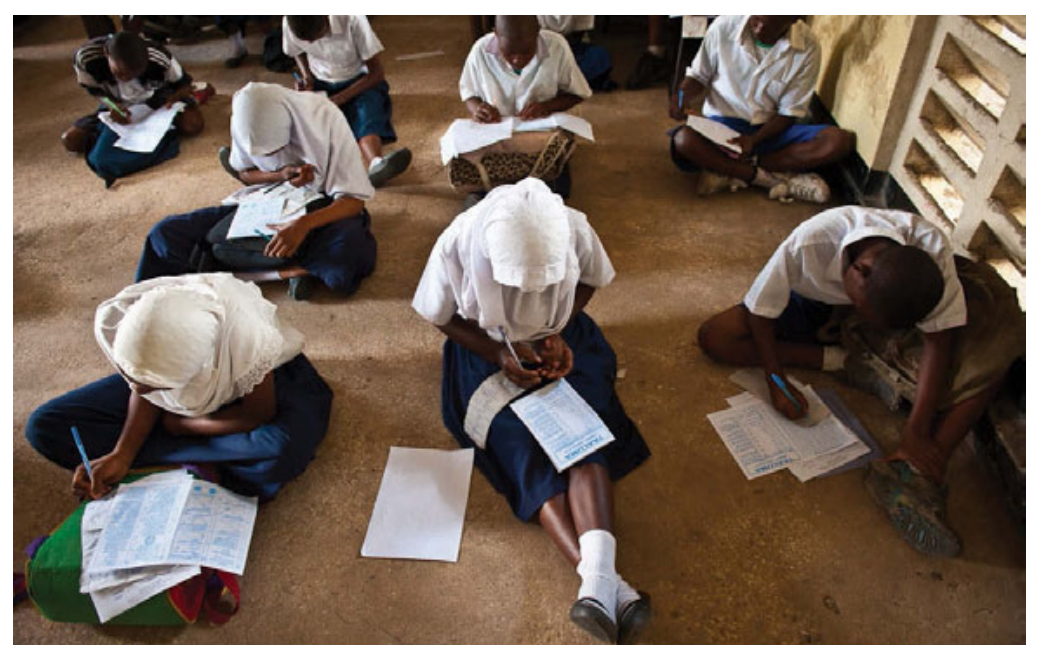




\section{Poverty Reduction Has Not Been Responsive to Tanzania's Remarkable Economic Growth, and Inequality Has Worsened}

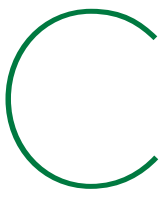

onsidering Tanzania's remarkable economic growth, reducing its poverty has been very slow. Growth in gross domestic product (GDP) averaged 6.3 percent from 2007 to 2017, dropping to 3.3 percent when adjusted by population size. These figures are based on the GDP series, base year 2015, released in February 2019. The new series shows a slight increase in GDP and less volatility in economic growth since 2012. The trend in the previous rebasing, released in December 2014, base year 2007, was similar, with GDP growth averaging 6.3 percent and GDP per capita growth 3.5 percent for 2008-13. However, persistent growth has had only a modest impact on poverty.

The growth elasticity of poverty dropped from a low $\mathbf{- 1 . 0 2}$ in 2007-12 to $\mathbf{- 0 . 4 5}$ in 2012-18. Thus, a 10 percent increase in GDP growth per capita can be expected to produce a 4.5 percent decrease in the proportion of the poor. This is very low-for developing countries, on average poverty is expected to drop by over 20 percent when per capita GDP rises by 10 percent.

In 2007-12 the pattern of growth in household consumption diverged significantly from GDP growth due to a discrepancy between price deflators, but the difference narrowed in 2012-18. How much poverty reduction responds to economic growth depends on whether economic growth is defined based on changes in GDP per 
FIGURE ES.12 Growth Incidence Curves, 2012-18,

Percent

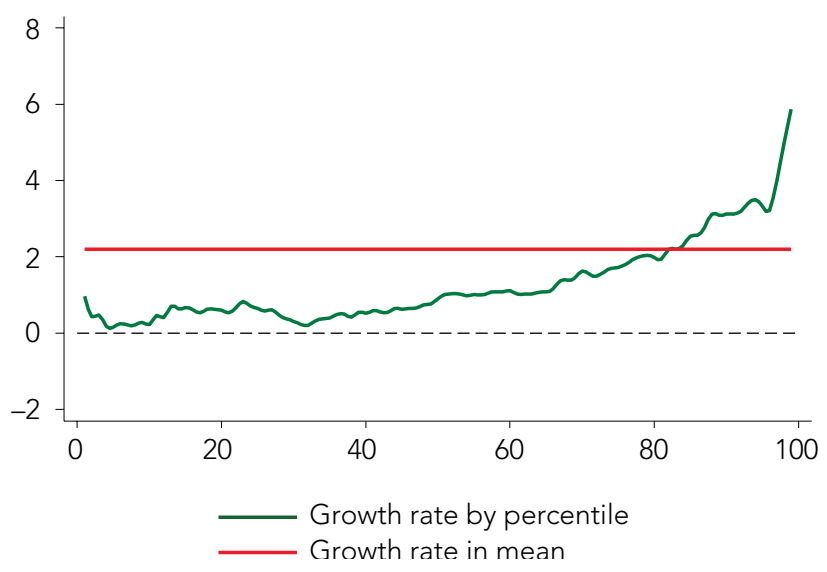

Source: HBS 2011/12 and 2017/18
FIGURE ES.13 Growth and Redistribution Effects, 2012-18, Percentage Points

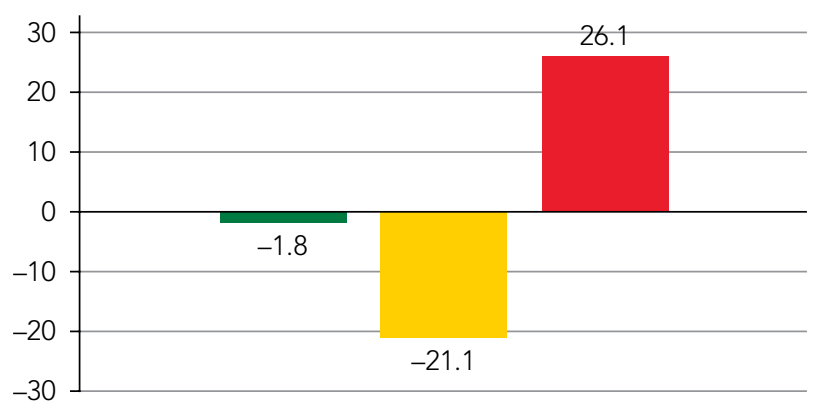

Change in poverty headcount

Growth

Redistribution

Source: HBS 2011/12 and 2017/18

the rise in inequality (the redistribution effect) (Figure ES.13). The deterioration in the Gini coefficient supports this: having gone down from 38.5 to 35.8 percent in 2007-12 it has risen to 39.5 in 2018. Throughout the region, inequality was lower than it had been initially in rural areas (at 33.5 percent) but jumped in urban areas, essentially in Dar es Salaam where the Gini coefficient reached 43 percent in 2018, up from 40 percent in 2007 and 36 percent in 2012.

Growth was driven by sectors where few in the general population work, particularly the poor. The fastest growing sectors were construction, information and communication technology (ICT), real estate, nonmarket services (e.g., education, health, and public administration), and to a lesser extent mining, transport, and trade. Each of these sectors employs on average no more than 3 percent of the population. However, 60 percent of their employees tend to be significantly more educated and better-off. These sectors employ over 20 percent of Tanzanian workers with lower secondary education and above. Within agriculture, where most Tanzanians work, particularly the poorer ones, the crops and livestock subsectors grew relatively fast at about 5 percent. However, even there, few of the poor produce market-oriented crops and livestock; they mostly operate subsistence farms.

Tanzanians with more education and skills were thus better positioned to benefit from fast-growing sectors. Better-off Tanzanians, who have more human capital and productive assets, were better able to take advantage of 
the opportunities generated by the fast-growing sectors. Their income and consumption rose significantly faster than for those with less education and fewer endowments, and employed in sectors growing more slowly. As a result, inequalities widened. Another result was the persistence of the urban-rural welfare gap: urban dwellers with more education and assets could better access productive jobs and maintain their higher economic status. Policies to empower the rural poor did partly reduce urban-rural gaps among poorer groups, but among the better-off inequality worsened.

\section{A greater proportion of households are operating their own businesses, which could be a pathway out of} poverty. In 2018, about 14 percent of households own nonfarm enterprises (NFEs), up from 9 percent in 2012. Here, however, there is a location and gender bias: the proportion of households operating NFEs is about three times higher in urban areas and fewer women own NFEs than men. Since 2012, the proportion of women engaged in NFEs has risen in rural areas but fallen in urban areas.

The profile of households operating NFEs closely resembles that of the better-off households: (1) The household heads were more educated, with lower secondary school completion rates of about 17 percent, compared to 12 percent nationally and less than 6 percent among farmers. (2) They had fewer children and thus fewer household members and lower dependency ratios. In 2018 the average size of an NFE household was about five, and of farming households six. (3) Households that operated NFEs, especially in urban areas, were at the top of the consumption distribution, with average monthly consumption about 2.5 times that of farming households.

\section{Despite being better-off, most NFE households continued to operate in the informal sector, lacked access} to formal funding sources, and created few jobs. In 2018 the majority of NFEs were either mobile with no fixed location (24 percent) or operated out of the owner's house (32 percent). Moreover, in 2012 only 11 percent had been registered with the business registration and licensing agency (BERLA), and in 2018 this had not changed. Moreover, in both 2012 and 2018, most NFEs were no more than two years old. Despite initially relying on personal savings or agricultural proceeds to start their businesses, after 2012 more NFEs began to use formal sources of credit to run their operations, though the increase is from a very low basis. The share of NFEs funded by owner savings fell from 36 to 33 percent and the share funded by Credit Co-Operative Society (SACCOS) and bank loans rose from 2 to 3 percent. Reliance on loans from family or friends also grew. It will take a long time for NFEs to create economies of scale and scope. Only a few employ workers who are not members of the household. In 2018, 27 percent of NFEs were working proprietorships, and 25 percent reported having unpaid household members working in the business. Only 7 percent hired paid workers who were not household members. 


\section{Slow Progress in Poverty Reduction Has Pushed Up the Number of Poor People, Leaving a Noticeable Share of the Population Still at Risk of at Least Transitory Poverty}

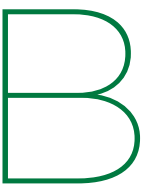

ecause the population grew faster than poverty was reduced in 2018, about 14 million Tanzanians lived in poverty, up from 13 million in 2007 and 12 million in 2012. In 2018,32 percent of the population lived in urban areas, up from 29 percent in 2012. As urbanization accelerated, the increase of the poor was proportionately higher in urban areas, but the majority still live in rural areas. In 2007-18, the urban population rose by about 7 million and the number of urban poor by 0.6 million-a result of both urbanization and the dilatory pace of urban poverty reduction (Figure ES.14). Most of the changes occurred outside Dar es Salaam, where the population has gone up by nearly 5 million and the number of poor by nearly
FIGURE ES.14 Number of Poor People, 2007-18, Million

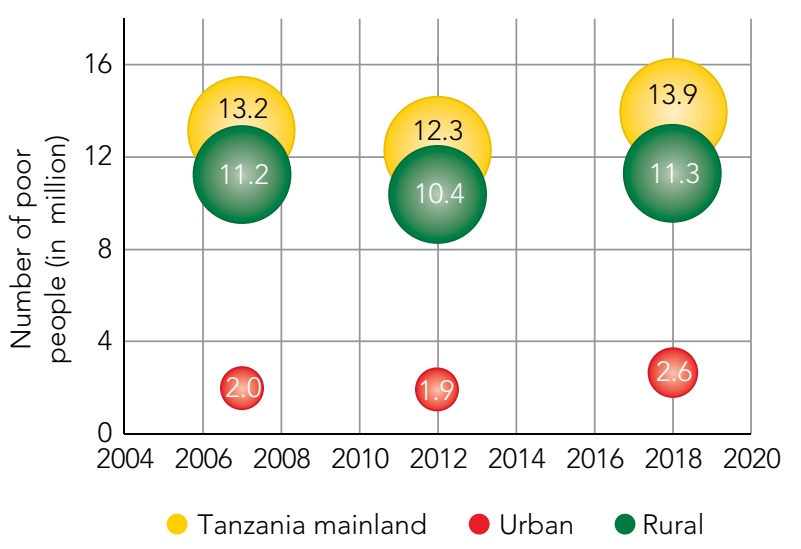

Source: HBS 2007, 2011/12 and 2017/18. 
0.7 million. In rural areas, the total population went up by only 26 percent, the number of poor people was almost unchanged, and the number of extremely poor declined. However, over 80 percent of the poor (11.3 million) continue to live in rural areas, where 3.5 million of them suffer extreme poverty; in urban areas, 2.6 million live in poverty and 745,000 in extreme poverty.

\section{A large proportion of the population is clustered} around the poverty line. Raising the consumption of poor households by just TZS 350 per adult equivalent per day would lift about half of the poor out of poverty. However, a quite significant proportion of Tanzanians who live just above the poverty line are at risk of being pushed into poverty by an economic shock (Figure ES.15). Mobility in and out of poverty is thus very high.
FIGURE ES.15 Consumption Density around the Poverty Line in 2018 (2011 PPP).
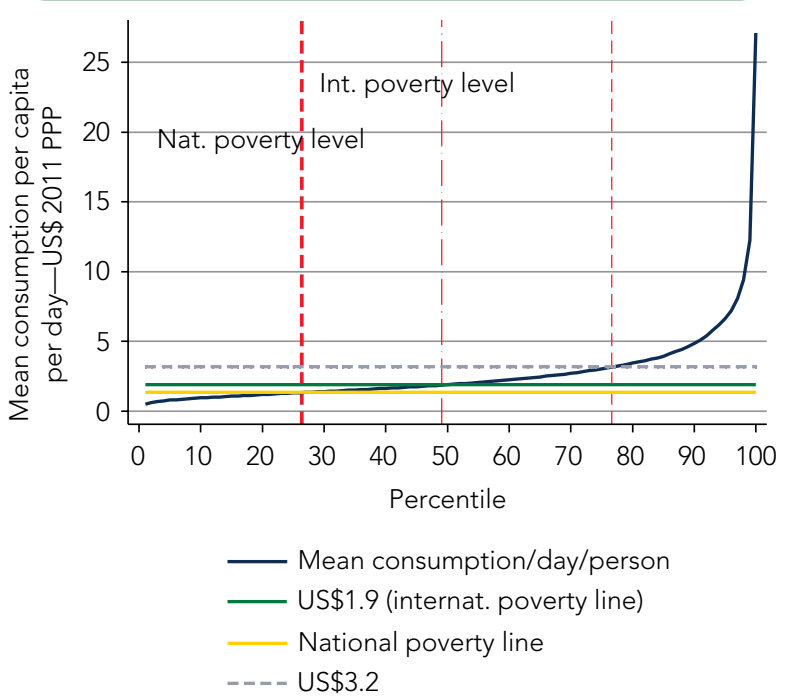

Source: HBS 2017/18

\section{Between 2010 and 2015,} the poverty status of nearly 30 percent of the population changed. Analysis of the dynamics of poverty based on National Panel Surveys (NPSs) found that about 16 percent of Tanzanians escaped poverty and about 12 percent fell into it. In both years, about 60 percent of the population were nonpoor and 12 percent stayed poor (Figure ES.16).

\section{FIGURE ES.16 Transition In and Out of Poverty, 2010-15, Percent}

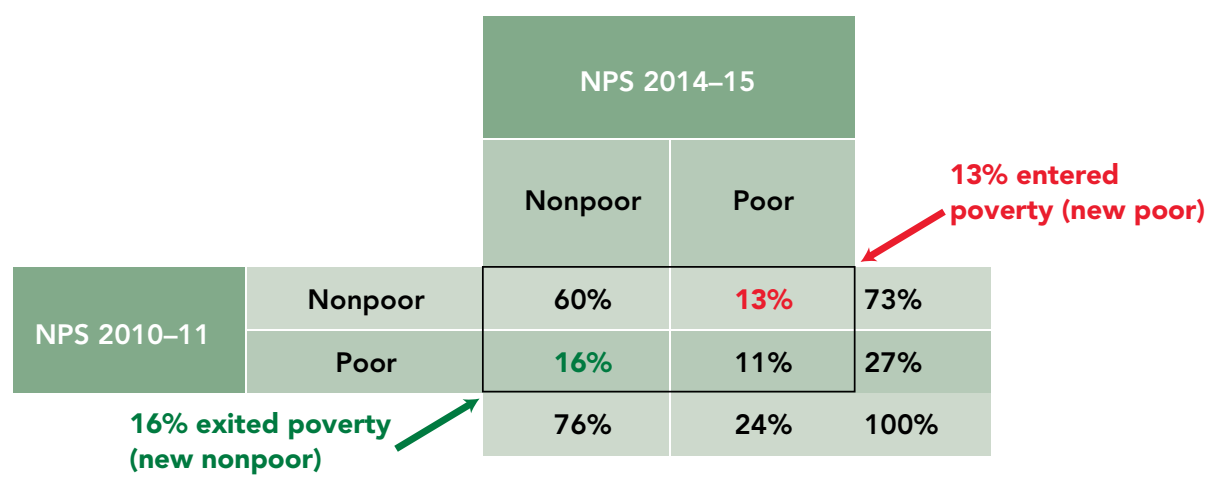

Source: NPS 2010/11 and 2014/15. 


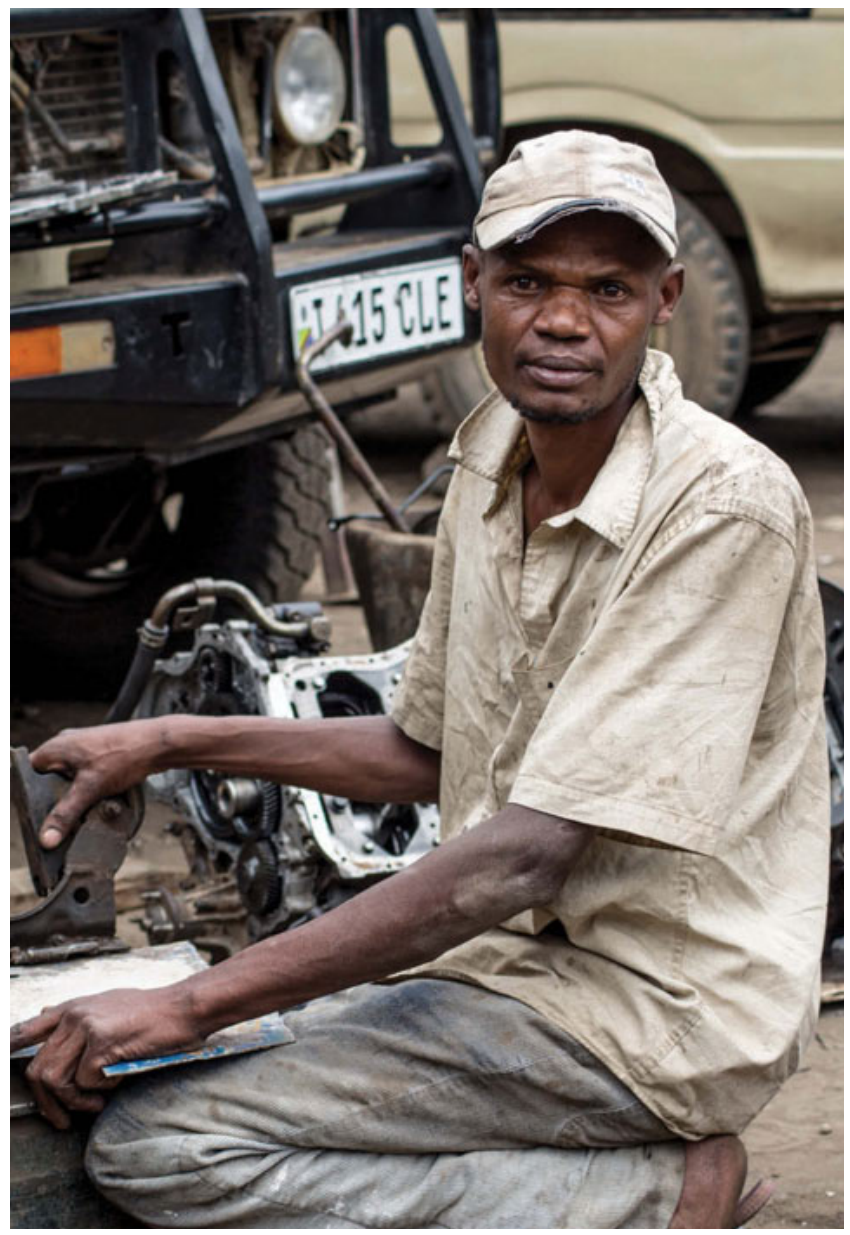

Transition out of poverty has generally been coupled with shifts to more productive activities, within agriculture or outside to services. Over

70 percent of those who moved out of poverty still considered agriculture their primary work activity, even though many supplied more hours to services and industry. Also, many moved from unpaid family helper status to self-employed or wage worker. The others moved from agriculture to services or, to a lesser extent, industry. On average, in all sectors they worked more hours, but even more in productive ones. Meanwhile, those who fell into poverty moved to less productive work, such as unpaid family helper, and continued to spend most of their time in farming. They also tended to work fewer hours. Yet exposure to shocks does not seem to have significantly affected transitions into and out of poverty. The numerous initiatives to empower the poor seem to have brought them closer to fulfilling basic consumption needs, but the big jump out of poverty is yet to be achieved. 


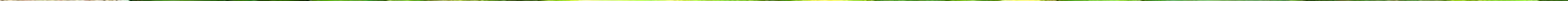




\section{It Is Hard for the Poor to Achieve a Better Life because of a Large Number of Dependents, Low Human Capital, Low-Profile Jobs, and Limited Access to Basic Services and Assets}

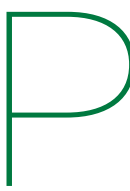

oor households are burdened by large numbers of dependents and disadvantaged by too little education. The number of children under 15 in poor households is almost double the number in nonpoor households. Poor households also have significantly higher dependency ratios. About 44 percent of households with five or more children under 15 are poor, 18 pp higher than the national average and $28 \mathrm{pp}$ more than the poverty rate for households with just one or two children. About 29 percent of household heads have no education, and 19 percent did not complete primary school, with rates being highest among poor rural households. Only 3.4 percent of the heads of poor households (and 1.3 percent of rural ones) went beyond primary education, compared to 20 percent for nonpoor households. Of households whose heads have no education or did not complete primary, about 35 percent live in poverty. The poverty rate drops to 26 percent for those who completed primary schooling and to just 6 percent among households with lower secondary education and above (Figure ES.17). While education is still the best shield against poverty, primary education seems no longer sufficient to open up opportunities. 
FIGURE ES.17 Education Level of Household Head and Poverty, 2018, Percent

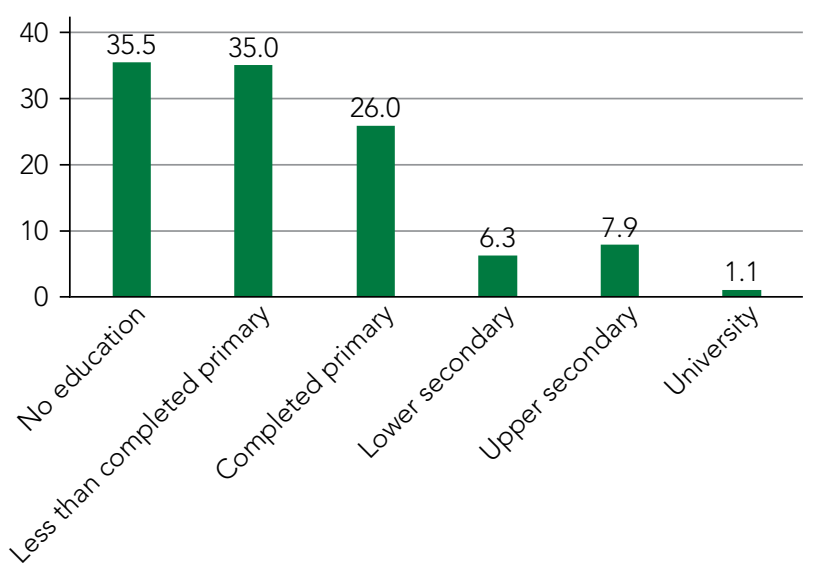

FIGURE ES.18 Sector of Employment of Household Head and Poverty, 2018, Percent

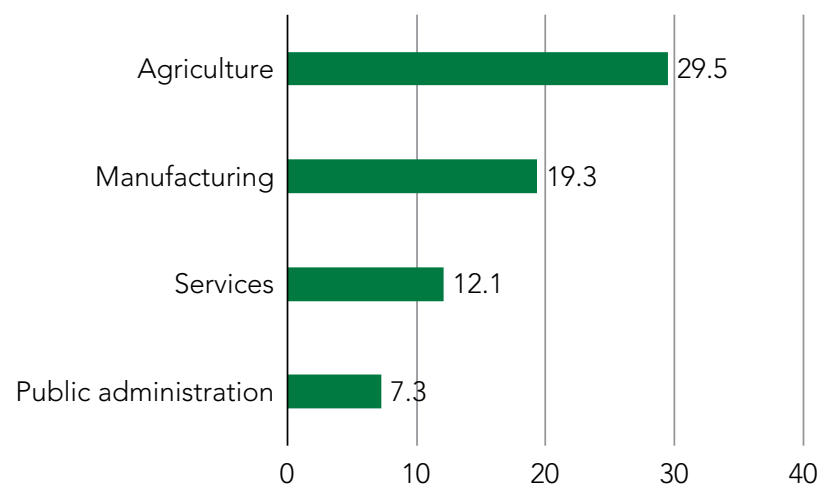

Source: HBS 2017/18

Source: HBS 2017/18.

Poverty seems to be more prevalent among women. It is difficult to understand poverty by gender because household surveys assume equal distribution of consumption between members of a household, and because of the status of women who head households. However, there are indications that poverty is more prevalent among women. Particularly in urban areas, more women-headed households are poor (20.3 percent) than men-headed ones (14 percent). Some types of women-headed households are particularly vulnerable to poverty-single and divorced women are poorer than men by about $11 \mathrm{pp}$. The gap is high in both rural and urban areas, but particularly in the latter and among divorced households, where it exceeds $22 \mathrm{pp}$. Urban widows are also poorer than urban widowers by about $14 \mathrm{pp}$. Ownership of assets, especially mobility and communication equipment, is also significantly lower among women-headed households, which indicates the limited access of women to productive assets.

\section{Less human capital and limited access to basic services limit opportunities for the poor to access productive}

jobs. About 80 percent of the heads of poor households work on their own farms or to a lesser extent as unpaid family farm helpers. In these households the poverty rate is more than double that of those in other employment categories. Households whose head is an entrepreneur with others or self-employed in nonfarm sectors are less likely to be poor. Similarly, poverty rates are lowest among households whose head works in trade and services (Figure ES.18). Although so many poor households are engaged in agriculture, about 18 percent of them fear almost every month that they will run out of food, compared to 10 percent of nonpoor ones; another 37 percent of poor households estimate they might run out in at least some months. In all, 50 percent of poor households ran out of food if not every month in at least some, compared to 32 percent of nonpoor households. 


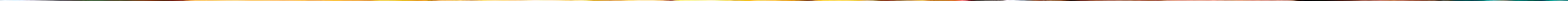


Human capital and access to productive jobs are lower for women than men, particularly in poor households.

Nationally, 23 percent of women have no education and 19 percent more did not complete primary school, compared to 13 percent of men with no education and 24 percent who completed less than primary. The gender gap is larger in poor households, where 32 percent of women have no education compared to 19 percent of men. As a result, more women than men are in unpaid household work and low-paying jobs. The gaps are particularly large among poor households, where they exceed $7 \mathrm{pp}$. However, the gender gaps in education and employment are significantly lower in the younger generation, suggesting that gender differentials are starting to shrink and that policies to enhance girls' education and empower women are beginning to bear fruit.

\section{Poor households suffer from less access to infrastructure and community services, which minimizes their}

opportunities. Social and community services, such as electricity, water supply, health facilities, roads, markets, and communication networks, are the backbone of household development; they structure the household environment and promote emergence of opportunities. Moreover, the existence of essential services and infrastructure often exposes the serious shortfalls in services for poor households, which are more likely to live in underserved communities, which perpetuates their dire lack of both cash and access to opportunities. Only 7 percent of poor households are connected to the electrical grid and 28 percent use solar energy; the rest rely on inefficient energy sources for lighting. Over 90 percent of poor households use firewood and charcoal for cooking. About 30 percent of poor households still have access only to unsafe sources of drinking water, and over 90 percent rely on unimproved sanitation facilities or none at all. Only about 13 percent of poor households have access to tarmac roads; 44 percent lack any source of access. Among nonpoor households, the corresponding rates are 22 percent with good access and 32 percent without any. Also, 41 percent of households have no access to a health center, dispensary, or hospital, whether public or private. Here, poverty status makes very little difference.

\section{For many, access to the Productive Social Safety Nets (PSSN) program is essential for meeting basic consump-} tion needs, but its coverage is limited. The program is managed by Tanzania Social Action Fund (TASAF), which reports that the program covers 1.2 million households, of which 250,000 benefit from public works program. HBS 2018 found that about 1 million households and 4.9 million people benefit from the PSSN cash transfer program, of whom 291,000 households (1.4 million people) also benefit from the public work program. PSSN reached 15 percent of extremely poor households, 14 percent of poor households, and 8 percent of nonpoor ones. In line with the national distribution of the poor, the beneficiaries are mostly rural, constituting 78 percent of households benefiting; coverage reaches 11 percent of all rural and 5 percent of all urban households. The fact that the PSSN benefit is mainly used to purchase food underscores the high food stress in Tanzania, especially for the poorest households. 
About 66 percent of beneficiaries reported using PSSN income support to cover their food needs, 13 percent to cover education and health expenses, and 21 percent to invest in productive assets and improve housing (8 percent). Of the poorest beneficiary households, only 4 percent invest in productive assets. While most nonpoor beneficiaries also use the funds mainly for food, about 10 percent invest in productive assets.

PSSN may have helped many beneficiaries to escape poverty. PSSN is intended to target the poorest Tanzanians. According to HBS 2018, after the program had been in operation for three years, about 57 percent of PSSN beneficiaries were in the two poorest consumption quintiles. However, about 69 percent of the households interviewed that reported benefiting from PSSN were above the poverty line, though still receiving PSSN support. For some this could be a temporary change of status; that is, for households that were close enough to the poverty line, the income support from the PSSN cash transfer may allow them to afford consumption above the poverty line, but they would likely fall back into poverty if PSSN support is removed. For about 25 percent of them the average consumption was only 20 percent higher than the poverty line; these households are at high risk of falling back into poverty if income support is taken away. In other cases, the PSSN may have allowed some households to move sustainably above the poverty line. About 23 percent of current beneficiary households are in the two upper consumption quintiles (15 percent in the 4th quintile and 8 percent in the 5th), which makes them 7 percent of all households in the 4th quintile and 3 percent of all in the 5th. Of PSSN beneficiaries, 10 percent of those in the 4th quintile and 18 percent in the 5th invested the PSSN cash in productive assets compared to only 4 percent of households in the poorest groups. Investing in productive assets may have helped these households to improve their living standards faster and graduate to higher income groups. More than six years since the program was designed, its targeting needs to be reviewed, but the process needs to be managed very carefully because some nonpoor beneficiaries may fall back into poverty if they are dropped from the program. Even households in the highest quintiles are at risk as their productive investments could be affected, something that would be even more problematic if these investments are used to support other poor households. The review of program targeting and recertification of beneficiary households needs a thorough analysis to identify appropriate candidates, supported by measures to build the resilience of those who may no longer qualify so that they do not fall back into poverty. It also needs to be guided by processes that are objective and standardized.

Without PSSN, basic needs and extreme poverty would have been higher. Without PSNN income support, poverty would have been about $2 \mathrm{pp}$ higher, which translates to an additional 1 million poor people, and extreme poverty would also rise from 8 to 9.2 percent, equivalent to 700,000 more people. Expanding coverage of the program and its targeting would help to accelerate poverty reduction. 
is of

at

at

$x_{-2+\infty}$

a
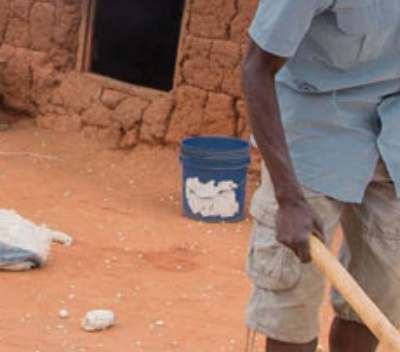

I. $\quad 2$

(2⿰氵)

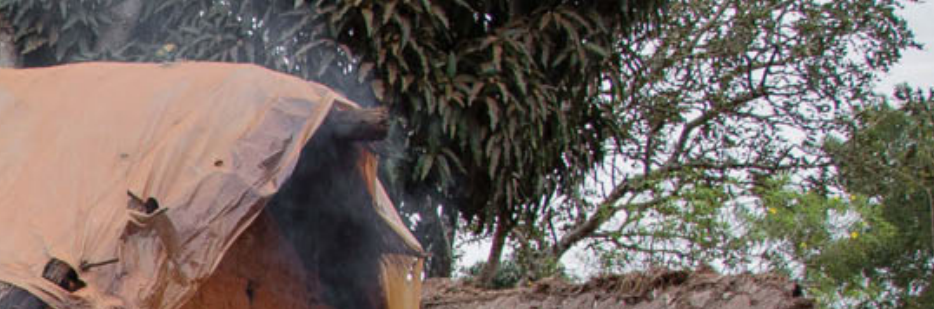

, 3.t.

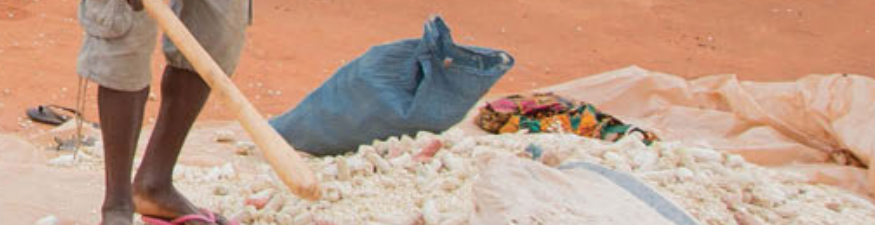

(2) 20

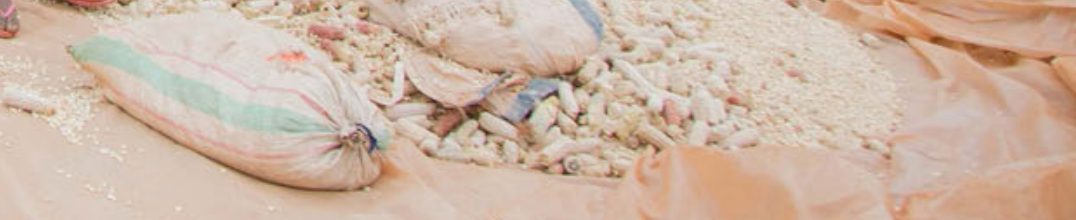




\section{The Drivers of Poverty are Mutually Reinforcing and Carry Across Generations}

he poor start life at a disadvantage, and many pass poverty onto their offspring. They are hobbled by, among other deficits, limited resources, malnutrition and health problems, poor access to social services and health care, and low education and skills. They lack income, can save little for the future, are vulnerable to shocks, and have limited coping strategies. Lacking the skills to take advantage of most work opportunities, they are generally limited to vulnerable and low-productivity jobs. These deficits limit the upward mobility of their children, perpetuating poverty for following generations. Tanzanians of less-educated parents are more likely to be less educated themselves, and those with better-educated parents are more likely to

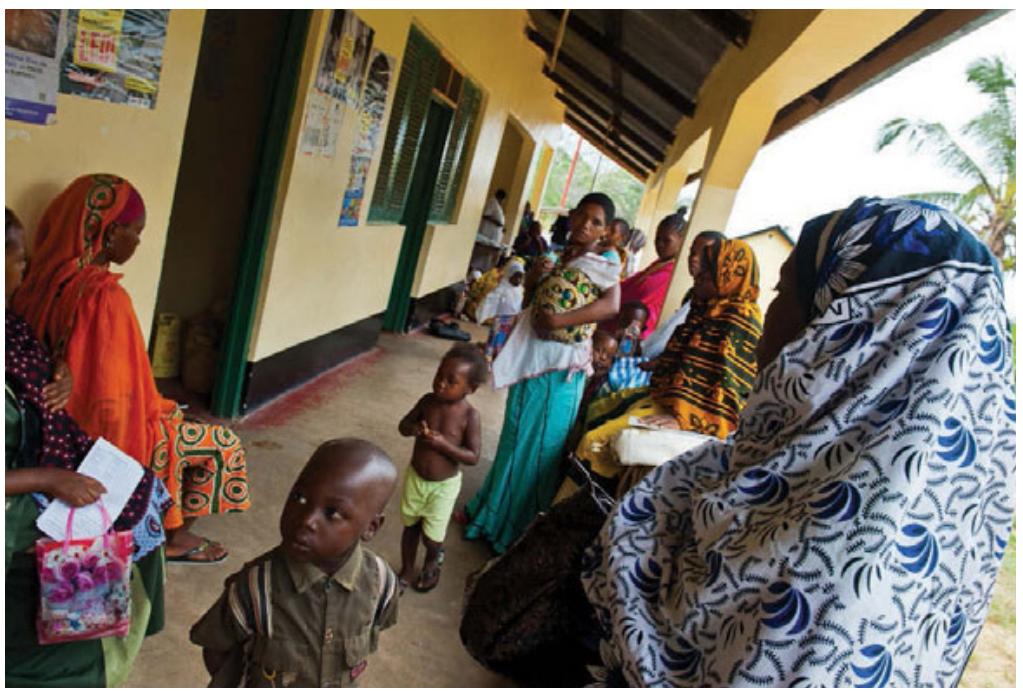
achieve higher education (Figure ES.19). Educational mobility is lower among the poor and women, so that low human capital perpetuates vulnerability and gender inequality. Intergenerational mobility across economic sectors seems very limited; Tanzanians often have the same employment status and jobs in similar sectors as their parents.

Estimates of inequality of opportunity have found that about 20 percent of total inequality in consumption is due to circumstances outside the 
FIGURE ES.19 Intergenerational Mobility in Education,

2018, Percent

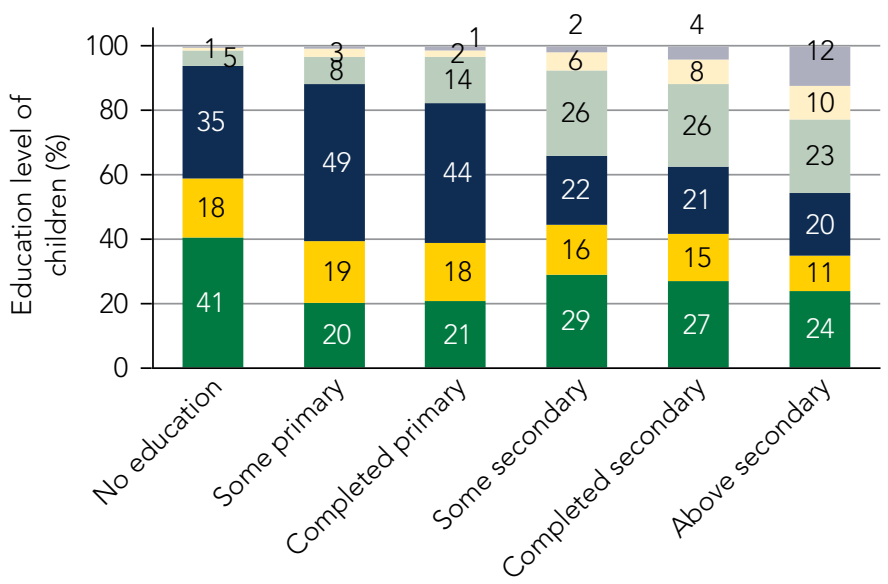

Education level of the father (\%)

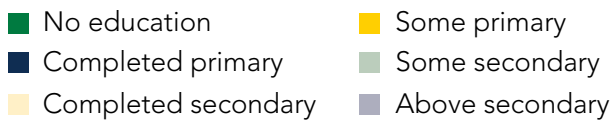

FIGURE ES.20 Contributions of Individual's

Circumstances to Inequality, 2018, Percent
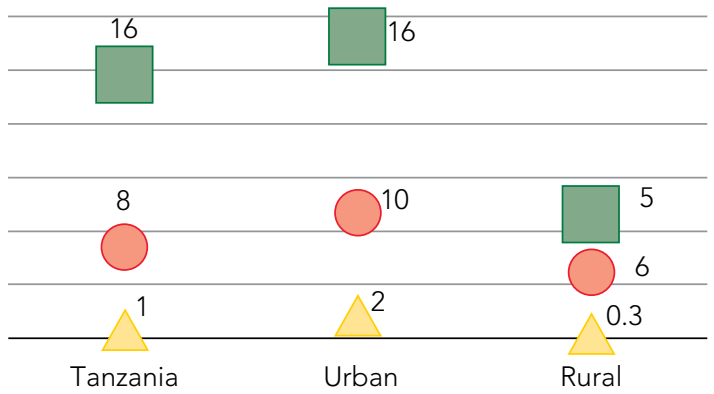

mainland

\section{$\triangle$ Gender \\ Birth place \\ $\square$ Family background}

Source: HBS 2017/18

Source: HBS 2017/18

individual's control, and about 16 percent is explained by family background. Parents' education and father's employment have the most influence on their children's outcomes and opportunities for economic mobility (Figure ES.20). This is a much larger share than in other Sub-Saharan African countries, where inequality of opportunity is significantly lower. Without additional policy actions, future generations of the poorest Tanzanians will likely be trapped in persistent poverty.

Inequality of opportunity is two times higher in urban areas than in rural ones. The share of inequality of opportunity in total inequality is 25 percent in urban areas compared to 11 percent in rural zones. This reflects two facts: (1) Family background variables have more influence on households and individuals who have more education and are engaged in more diversified occupations and jobs as it is the case in urban sectors. (2) To the extent that unobserved circumstances and institutional measures (e.g., family composition, parental financial situation, supply and quality of schooling, and labor and land market institutions) shape opportunities for rural Tanzanians, estimates of inequality of opportunities that do not take these circumstances into account are significantly biased downward. 


\section{Beyond the Urban-Rural Divide, Geographic Disparities in Poverty Are Substantial}

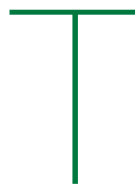

here are major disparities in the incidence of poverty and the distribution of poor people across the country. By region, poverty ranges from as high as 45 percent in Rukwa to as low as 8 percent in Dar es Salaam (Figure ES.21). Overall, about 33 percent of the poor are concentrated in the highly rural lake zone, where less productive and subsistence activities are common. In the lake zone, 4.6 million live in poverty and 1.3 million in extreme poverty; in the northern and eastern zones, less than 1.4 million live in poverty and 420,000 people in extreme poverty. Estimates for districts reveal broad pockets of poverty in the north, west,

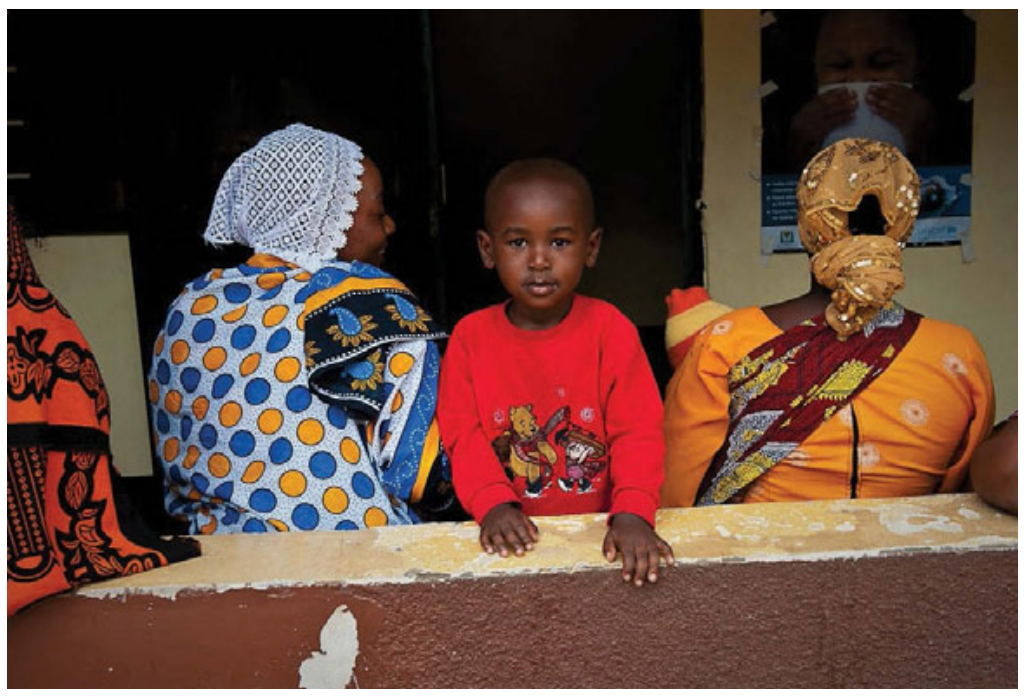
and south. Poverty was most pervasive in Longido in the Arusha Region to the north, followed by Kibondo in Kigoma Region and Sumbawanga Rural in Rukwa Region to the west, where poverty exceeds 50 percent (Figure ES.22). Generally, regions with the highest poverty rates also host the largest numbers of poor, particularly in the area around Lake Victoria and Simiyu region in the north; Kigosi, located between Shinyanga and Tabora regions; and Moyowosi in Kigoma region. However, there are also significant numbers of poor people in Lushoto district in Tanga and Ilala district in Dar es 

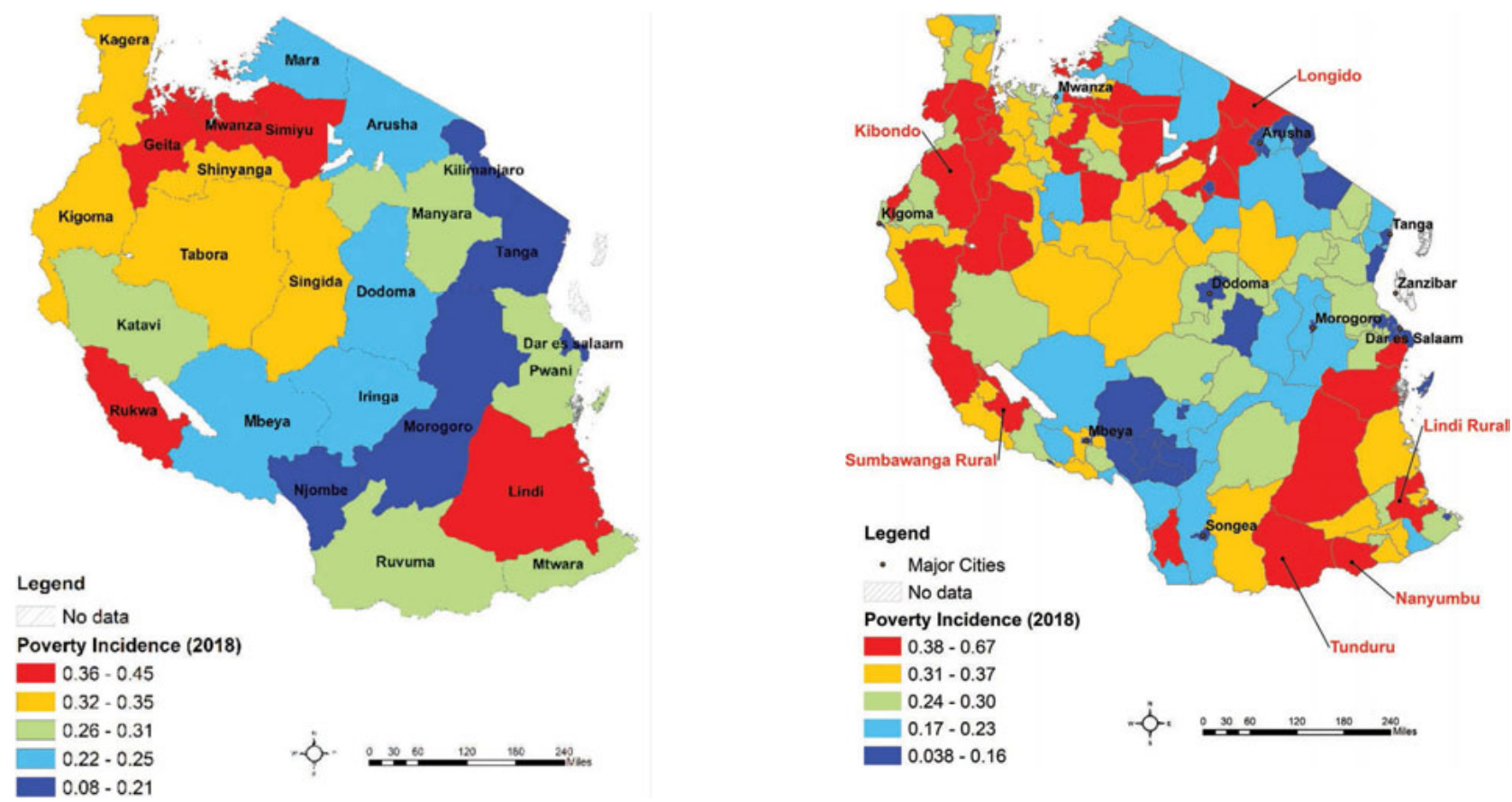

Source: HBS 2017/18 and auxiliary variables.

Salaam because their populations are larger. Conversely, Longido district in Arusha region and Nanyumbu district in Mtwara region, where poverty is high, are sparsely populated and therefore have fewer poor people.

\section{Urbanization and its associated structural transformation led poverty to drop faster in leading areas and gaps} to widen in lagging ones. For the past decade, urban growth has averaged 5.5 percent-higher than the national average of 3 percent population growth. In 2018, 32 percent of all Tanzanians lived in urban areas and by 2045 this share is expected to reach 50 percent. Poverty is lower in larger and more densely populated districts and in areas with a greater concentration of lights at night, which demonstrate both greater urbanization and more economic activity. In general, successful urbanization translates into poverty reduction through the structural transformation in which workers shift from low productivity agricultural activities to higher productivity urban jobs. In large cities, 


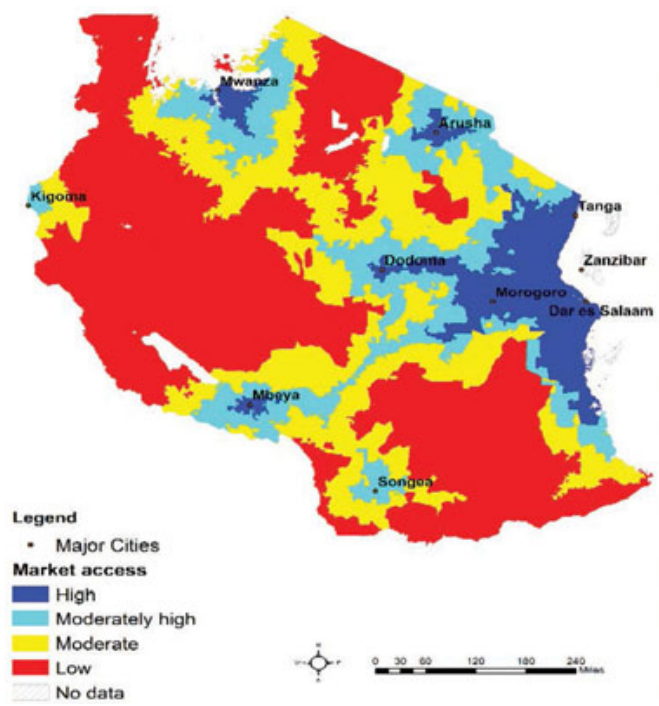

Source: World Bank's estimates based on OpenStreetMap. Note: The Open Source Routing Machine (OSRM) algorithm is used to compute travel time between each village and major cities. more productive jobs are available, and the productivity gains come partly from the benefits of agglomeration economies, such as resource-sharing, quicker and more accurate job matching, and greater knowledge spillovers. Tanzania is no exception.

Access to markets is limited, particularly in the northwest and southeast, areas typically characterized by severe poverty. Farmers in rural areas with limited market access suffer from relatively higher prices for fertilizers because of higher transportation costs and fewer product options (Figure ES.23). These farmers also have little access to output markets and must take less competitive prices. Lack of market access thus traps rural farmers in poverty and exacerbates inequalities between rural and urban areas.

\section{Road infrastructure and transport services also affect access} to markets. The poor quality of rural roads deters connectivity between rural areas and urban markets. Rural roads tend to be rudimentary, and transport services and facilities are unreliable and inadequate; in many remote parts of the country high post-harvest losses are an estimated 35 percent of total production. Thus, few and poorly maintained rural roads are a serious deterrent to the development of commercial agriculture.

\section{Areas surrounding Dar es Salaam, the commercial and economic center of the country, tend to have better} access to markets. The region's road network is wide and dense, which allows people living near the city to benefit from its agglomeration economies. The positive economic dividends of access to jobs and trade opportunities are hard to overstate. While the Dar es Salaam administrative region accounts for only a small fraction of mainland Tanzania's land area ( 0.16 percent) and only about 8 percent of its population, the region accounts for about 40 percent of its manufacturing jobs and 53 percent of manufacturing value. Dar es Salaam also handles 95 percent of its port traffic, dwarfing the importance of other cities as sources of imported goods. 


\section{Across the country, climate is also a driver of} geographic inequalities in welfare and pov-

erty. In Tanzania, poverty is more pronounced in tropical savannah zones, which are dominant in the northwest and southeast. Agriculture in the tropical zones tends to be less productive due to poor soil quality because of high temperatures and heavy rain. These zones are not suitable for producing wheat, which grows only in temperate climates, or maize and rice, which prefer temperate and subtropical climates.

Thus, production of maize, the most productive crop and a critical driver of poverty reduction

in Tanzania, is concentrated in the southern

highlands (e.g., Iringa and Mbeya); the southwest (e.g., Shinyanga and Rukwa); and Arusha, where the climate is nontropical and the land is most fertile. The fact that tropical zones also host a variety of agricultural diseases, particularly the vector-borne diseases prevalent in tropical countries, has serious implications for health and labor productivity.

\section{The climate also has a major influence on the vulnerability of the poor to natural disasters. Although there} is no direct correlation between poverty and natural disaster risks, many of the pockets of poverty in Tanzania are repeatedly subject to such risks. Drought is the most frequent natural disaster in poverty-stricken areas. Parts of Tanzania that were previously highly productive, such as the southern and northern highlands, will increasingly become tropical areas because of declining rainfall, frequent droughts, and significantly more spatial and temporal rainfall variability. In Tanzania drought has significantly worsened food insecurity, livestock and crop losses, and transmission of infectious diseases. Drought is more common now in parts of Arusha, Manyara, Shinyanga, Simiyu, and Dodoma regions. Among the most drought-stricken districts is Longido in Arusha region, where poverty is also estimated to be high. 


\section{Structural Transformation of the Economy Can Help Reduce Poverty Faster, but at the Micro Level the Transformation Is Slow}

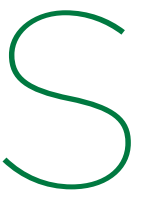

tructural transformation, an integral part of the development process, will determine whether Tanzania can pull itself out of poverty. A central aspect of any policy for curbing poverty and reducing the absolute number of poor would be creation of enough productive jobs to absorb the emerging young generation of workers. The need for more-and more productive-jobs is even more pressing in Tanzania given rampant demographic expansion and the fast-growing workforce. Structural transformation, which is at the core of this process, is a dynamic process that refers to both reallocation of labor from less to more productive sectors, and the productivity and job gains associated with this move. The larger the productivity gap between sectors-especially between agriculture and manufacturing and services - the greater the opportunity to achieve large gains as labor shifts across sectors.

\section{National accounts show that agriculture is contributing far less to value-added than services and industry.} In 1998, agriculture accounted for 40 percent of GDP; in 2017, it accounted for 28 percent. Meanwhile, industry accounted for 29 percent and services for 43 percent. Although services account for the largest share of GDP, in the past two decades its contribution to the economy went up by just 3 pp. Since 2016 industry has grown much faster; since 2000 its contribution to GDP has gone up by more than 50 percent (Figure ES.24). While micro data show similar trends, people are shifting more slowly from agriculture to services and industry. Integrated Labor Force Surveys (ILFS) show that between 2006 and 2014, employment in agriculture fell from 76 to 67 percent. Labor appears to be 
slowly shifting to services, where employment went up by 9 pp, and to a lesser extent industry, up by 1.2 pp. HBS 2012 and 2018 indicate similar trends: a decline of employment in agriculture from 75 to 58 percent and increase of employment in services and industry by, respectively, $12 \mathrm{pp}$ and $4 \mathrm{pp}$. But while the participation of labor in agriculture remains very high, people tend to supply more hours to services, followed by industry (Figure ES.25).

\section{Because of the slow transition of labor, the enormous poten- tial of structural change for productivity growth has yet to be} realized. There are sizable productivity gaps between economic sectors. Compared to agriculture, services productivity measured by value of output per worker is an estimated 9.5 times higher, and in industry it is 5.6 times higher. When productivity is measured by value of output per hour worked, compared to an hour worked in agriculture, one hour worked in services is estimated to be on average 3.2 times as productive, and one hour worked in industry about 2.4 times. Clearly, if there was a faster transition of labor away from agriculture, the productivity gains would be enormous. However, the transition of labor is low because of both worker capacity and skills limitations and the limited capacity of service and industrial firms to absorb the large and fast-growing workforce.

\section{In a more granular disaggregation, min-}

\section{ing, transport, and trade are the most}

productive sectors. On average, a mining worker is 8 times more productive than an agricultural worker, a manufacturing worker 4.8 times, and a worker in construction or utilities 5.4 times. When productivity is measured in terms of output per hour worked, the gaps are smaller and less varied: for example, one hour of mining is 3.1 times more productive than one hour of farming, and manufacturing is just 1.7 times more productive.
FIGURE ES.24 Contribution of Economic Sectors to GDP, 1998-2017, Percent

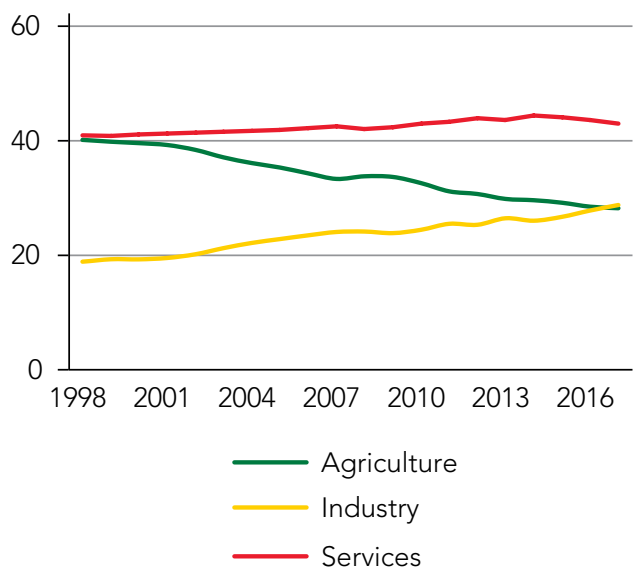

Source: National Accounts, 2019.

\section{FIGURE ES.25 Working Hours, Primary and Second Jobs,} 2010-15, Percent

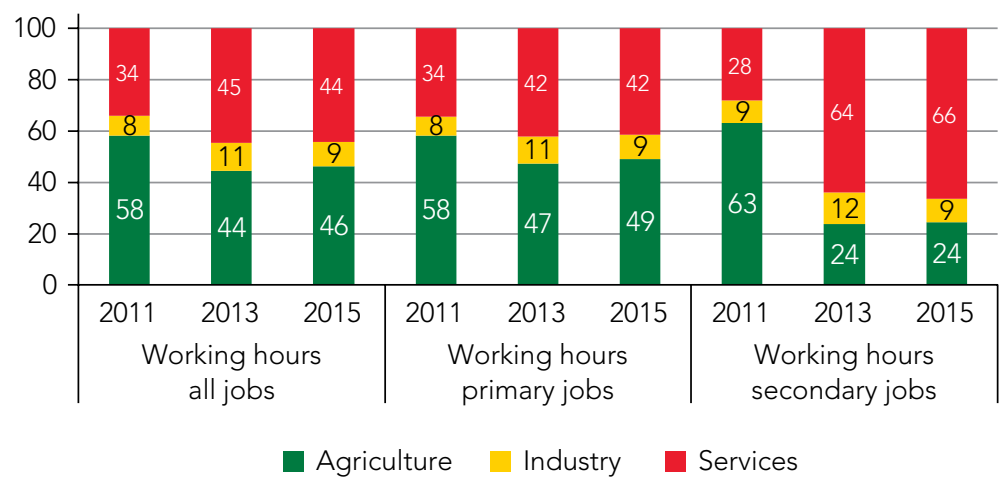

Source: NPS 2010/11, 2012/13, and 2014/15. 


\section{Industry Consists Primarily of Micro and Informal Enterprises Operating in Precarious Sectors and Relying on Unskilled Labor}

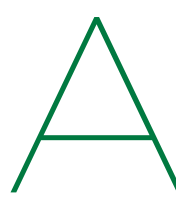

\section{bout 96 percent of Tanzanian firms have fewer than 10 workers and only 1 percent have more}

than 50. Among the smallest firms, 60 percent have only one or two workers. Because nearly half of the firms are not registered anywhere, they are considered informal. Tanzanian firms tend also to be fairly

young, with a median age of four years. In general, particularly in wholesale and retail trade and manufacturing, micro and small firms are likely to be informal and younger. Their small start-up capital is financed essentially from personal income. Meanwhile, large businesses tend to be older and mainly engaged in formal nonmarket services such as education or health (many are state owned); it may be that formal firms operating in public services have higher chances of surviving and growing.

Two-thirds of Tanzanian firms are in manufacturing and trade. About 35 percent are in manufacturing and 34 percent in wholesale and retail trade. Manufacturing firms primarily produce food and beverages (39 percent); textiles, wearing apparel, and leather (30 percent); and furniture (14 percent). Only 1 percent are in high value-added and knowledge-intensive industries. The rest operate essentially in services, especially nonmarket services. Less than 1 percent are in agriculture; most people working in that sector run their own farms without creating a business. 
Less than $\mathbf{3 0}$ percent of the workers in industry are skilled. About 13 percent of industrial firms cite shortage of qualified labor as their main problem; for medium and large firms, the proportion rises to 33 percent. This suggests that as firms grow, they engage in more sophisticated production that requires higher skilled workers, who are rare in the local market. This shortage of qualified labor severely undermines the performance of large industries, particularly mining, utilities, and more technically advanced machinery, electric equipment, and medical and pharmaceutical industries. However, nearly 40 percent of large manufacturers of furniture also consider the shortage of qualified labor to be a major concern.

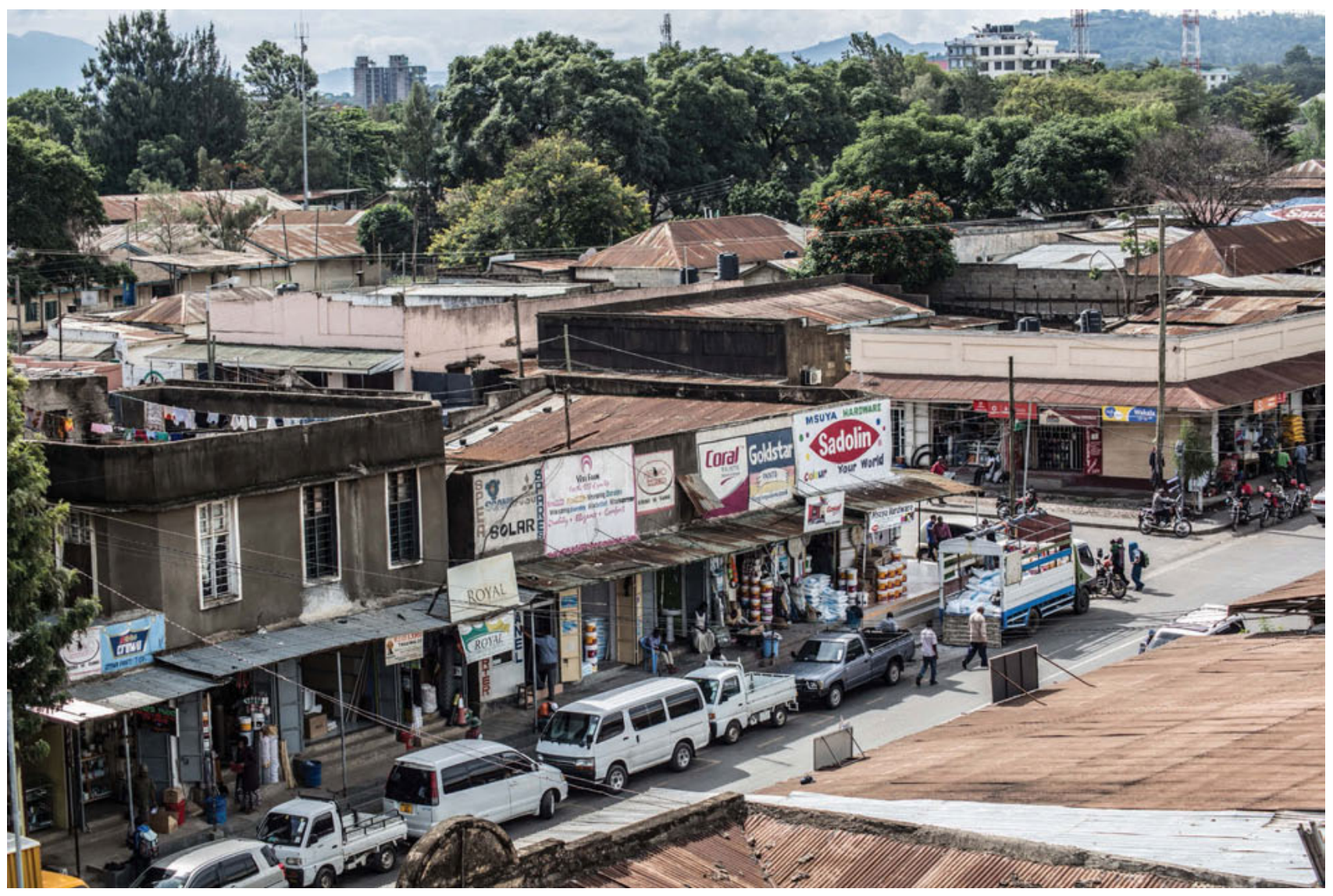




\section{As with Poverty, the Distribution of Firms and Employment Nationally Is Uneven}

The are pronounced disparities in where firms are located. The highest number are in the eastern zone at 27 percent, and the lake zone at 17 percent. In contrast, the southern and western zones each have no more than 5 percent of Tanzanian businesses. Regional disparities are even more pronounced; nearly 20 percent of firms are based in Dar es Salaam.

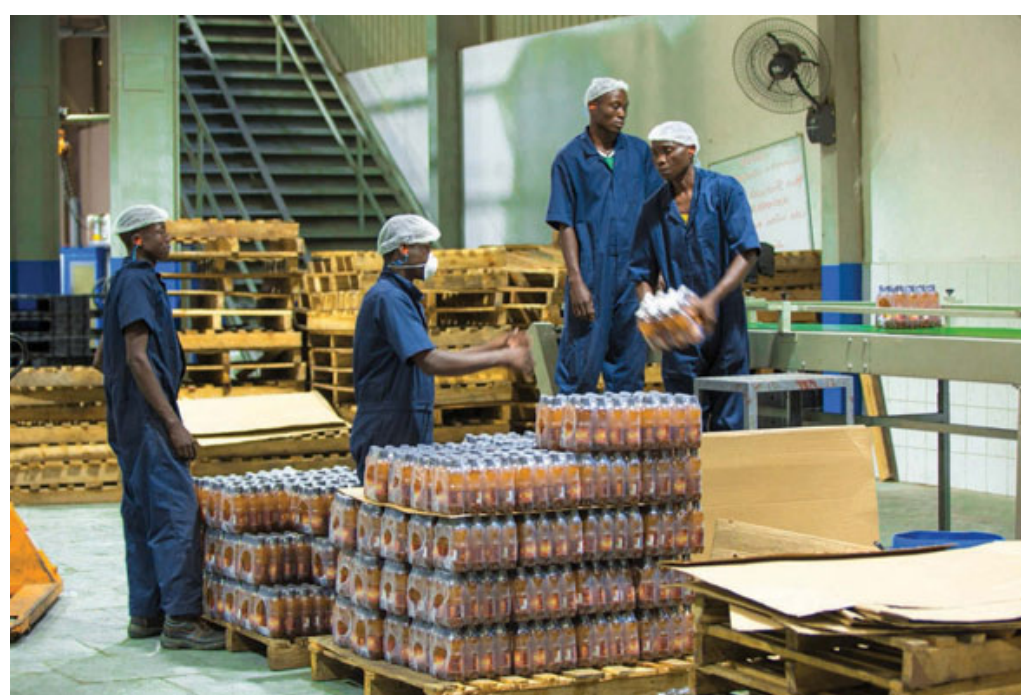

The geographic distribution of firms resonates with the distribution of poverty. There seems to be a negative and statistically robust correlation by region and district between the incidence of poverty and the number of businesses: the more businesses in a district or region, of any type, the less poverty there is. Although micro and small firms are known to not pay well, their presence nevertheless contributes considerably to improving living standards and reducing poverty. However, poverty declines more when there are more medium and large 
FIGURE ES.26 Relationship Between Poverty and the Number of Firms

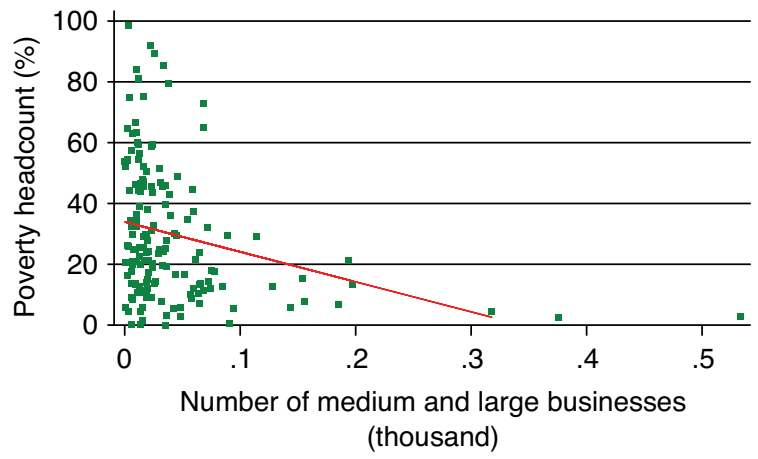

Source: Statistical Business Register 2014/15 and HBS 2017/18.

businesses (Figures ES.26 and ES.27). The results are supported by the 2015-16 DHS findings, which show that in the eastern zone, which has most of the businesses, 7 in 10 people are in the two highest wealth quintiles. Conversely, in the southern and western zones, which have the fewest businesses, around half of the population is in the two lowest wealth quintiles.
FIGURE ES.27 Geographic Distribution of Firms

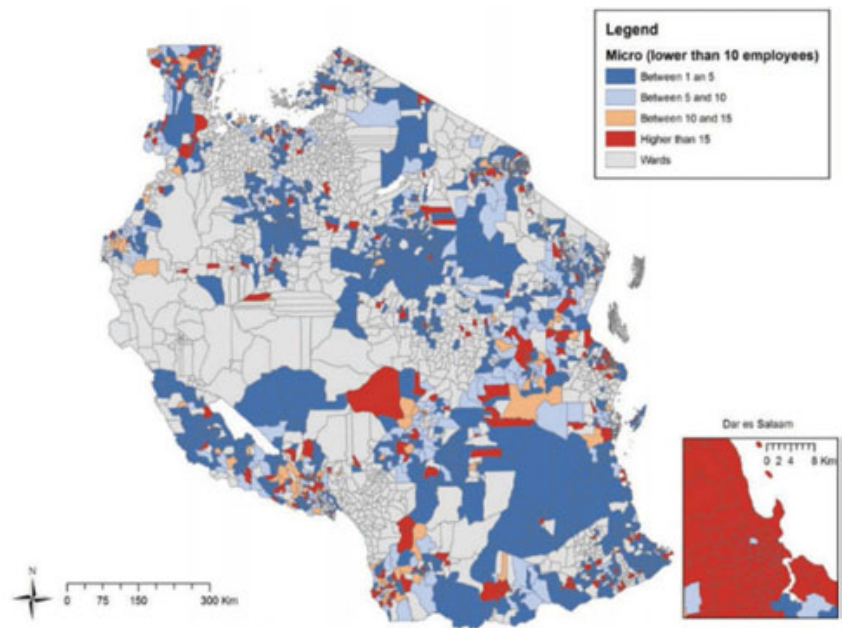

Source: Statistical Business Register 2014/15 and Tanzania Jobs Diagnostic (2017)

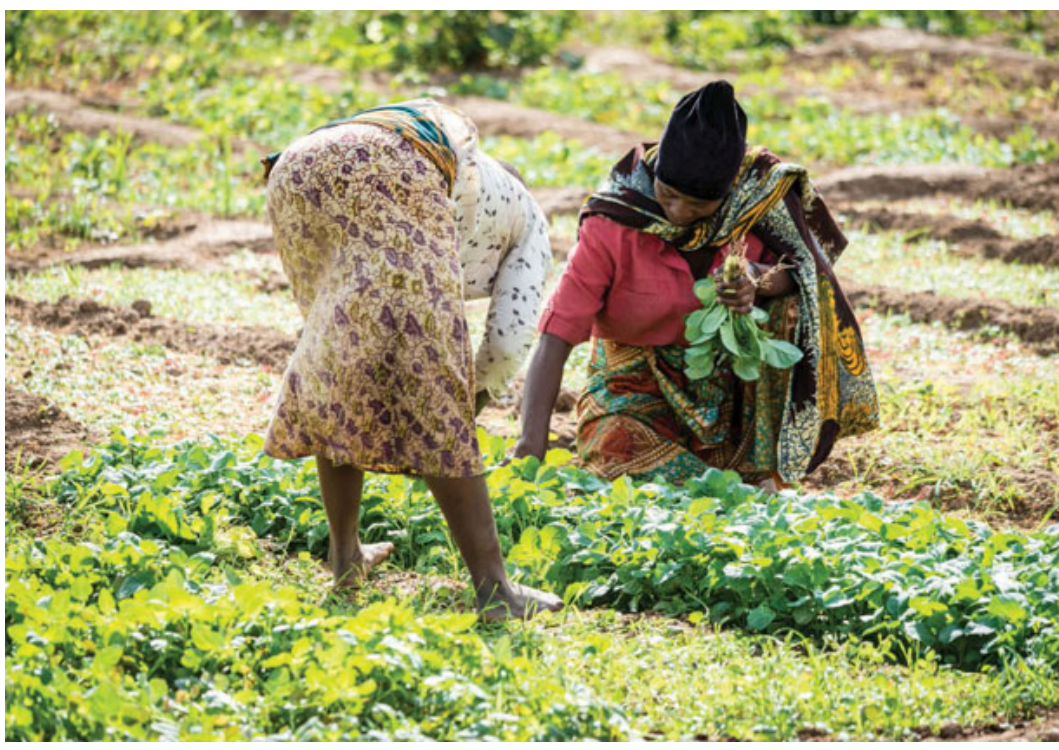




\section{Although Small Firms Dominate the Economy and Provide Most of the Jobs, Medium and Large Firms Could Create Jobs Fast}

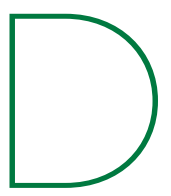

espite the predominance of micro firms in the economy, they account for just 24 percent of employment; large firms account for 28 percent. About half of Tanzanian jobs (49 percent) are in medium and large firms, which account for about 4 percent of all businesses (Figure ES.28). Thus, even though fewer than 0.5 percent of all firms employ more than 100 workers, they account for about 28 percent of all employment-their average number of workers is over 370, compared to no more than 2 in micro firms and 9 in small ones. New firms in business for less than five years account for less than 25 percent of jobs, compared to 36 percent in firms that have lasted more than twenty years. Though only 50 percent of firms are formal, they account for over 80 percent of jobs. In general, firms tend to employ twice as many men as women; the gender discrepancy is slightly higher in small and young firms. The average number of men is two times higher than that of women in these firms, while it is 1.6 times higher in larger and older firms.

In industry large firms contribute the highest proportion of value-added. In 2013, total industrial value-added was TZS 8,220,560 million, 84 percent of it from large firms (Figure ES.29). Value-added per worker in large firms is double that of medium firms and about 20 times higher than in micro firms. Apparently, over time firms that manage to grow become markedly more productive. Yet they account for only 0.5 percent of industrial firms; that may explain why industry in general is persistently unproductive. 


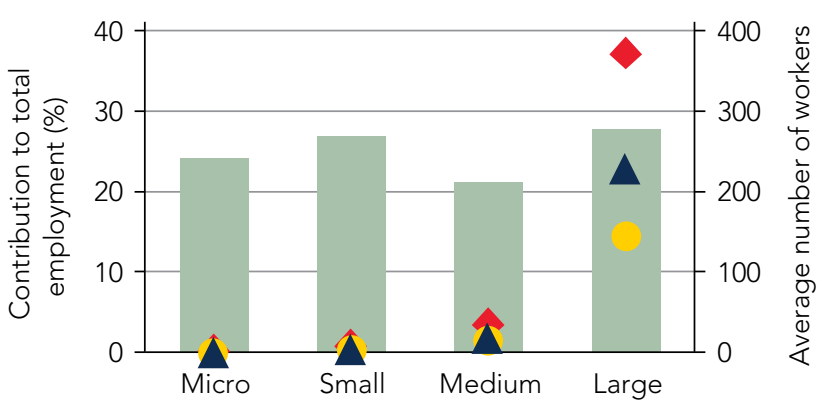

Percent of employment

- Average number of workers

- Average number of women

$\Delta$ Average number of men

Source: Census of Industrial Production 2013
FIGURE ES.26 Value Added by Firm Size, Billion TZS and Percent

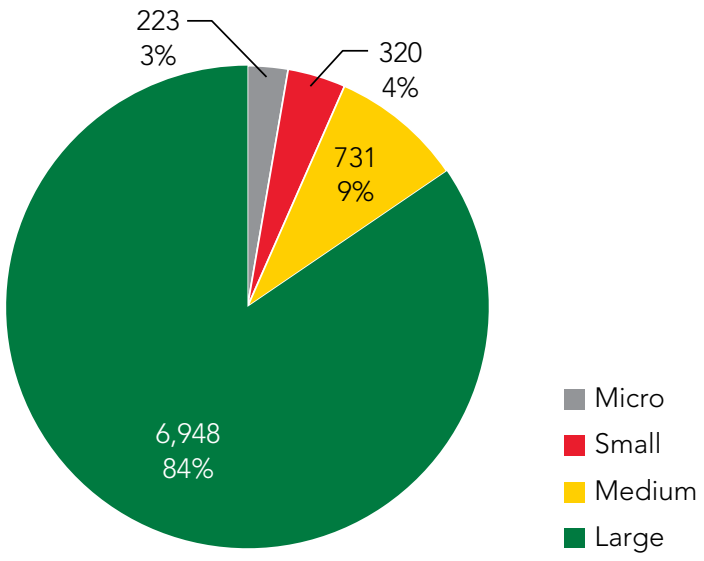

Large

Net job creation is mostly attributable to larger, older firms. In 2010-13, small firms created 34 percent of new jobs and medium and large firms about 67 percent.

However, micro firms lost jobs; they were down by about 1 percent. Firms in business less than five years created 8 percent of new jobs. Firms more than fifteen years old accounted for more than 50 percent of the jobs created.

\section{Small firms are hemmed in by the economic environ-} ment and the lack of support for entrepreneurs, and large firms by factors related to competitiveness. Both

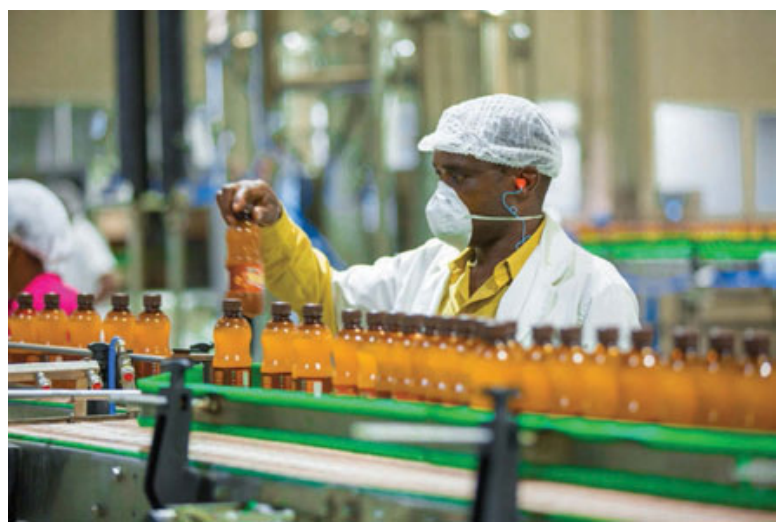

small and large firms perceive the high cost of production as the leading barrier to better performance. However, they differ in their perception of the importance of other problems. More than 30 percent of micro and small firms cite the uncertain economic environment, inadequate technology, lack of support to the private sector, and insufficient demand and production capacity as major concerns. However, more than 30 percent of medium and large enterprises report inadequate physical infrastructure, currency fluctuations, unfair competition, and lack of raw materials and qualified labor as their main problems. Inadequate financial services also rank high as a challenge to industry, but the problem affects small firms more than large ones. 


\section{Limited Access to Finance and the Need to Rely Heavily on Family Networks and Informal Funding Are Barriers to Emergence of a Vibrant Private Sector}

\footnotetext{
- anzania's formal firms perceive access to finance as a major and increasingly important obstacle. In the 2013 Enterprise Survey, about 70 percent of respondents identified access to finance as an important problem for their current operations, far higher than in 2006, when about 54 percent of respondents identified access to finance as a moderate or major obstacle.
}

The larger the firm, the less is access to finance a constraint. In 2013, only 28 percent of Tanzanian companies with fewer than 10 employees saw access to finance as either not an obstacle or only a minor one, but 69 percent of companies with more than 200 employees were not at all concerned about it. Similarly, only 23 percent of large companies saw access to finance as a major or severe obstacle, compared to 39 percent of micro and 52 percent of small firms.

Financial constraints do not seem to be suppressing the growth of Tanzanian firms. Even though a majority of Tanzania's firms are perceived as financially constrained, from the results of the 2006 and 2013 Enterprise Surveys, lack of access to finance does not seem to be a major determinant of growth. As firms grow larger, access to finance tends to be less of an obstacle_-perhaps because larger firms tend to have more access to evolved financial tools, such as overdraft facilities and credit lines in formal financial institutions. 


\section{Informal household enterprises have very little access}

to loans. Only 10 percent secured a loan to develop or support business operations. The rate rises to 12 percent for urban household enterprises and household services businesses. The credit comes mostly from micro credit entities or informal credit channels like SACCOS, private money lenders, or informal micro credit institutions. About 40 percent of the household enterprises that borrowed used the micro and informal credit channel; just 18 percent secured loans from a traditional bank. Most household enterprises are financed from personal savings or income, or from other households as gifts or loans.

\section{Financial inclusion is only moderate; many Tanza-} nians lack formal financial relationships. Owning a

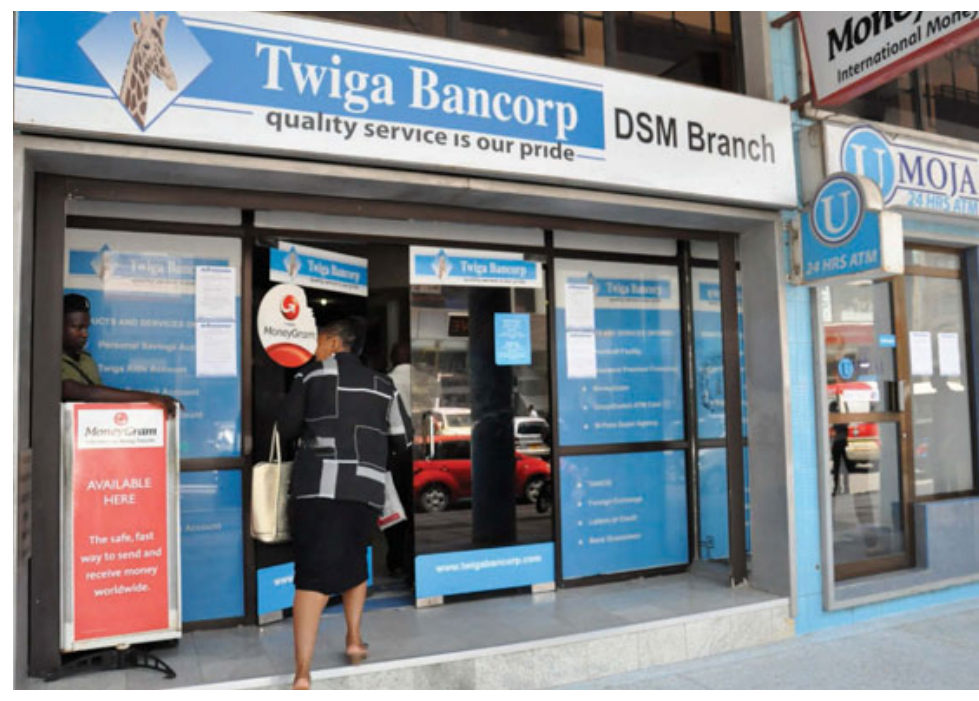

bank account, having formal savings, and being able to access credit from a financial institution are the three main indicators for measuring an individual's access to basic and critical financial tools. According to the 2017 Findex survey, 47 percent of the population had a formal bank account, just 6 percent had formal savings, and 5 percent had access to formal credit. HBS 2018 found that in the previous 12 months, 12 percent of household members had savings or current accounts and only 2 percent took out loans.

Financial inclusion is heavily determined by socioeconomic characteristics. Older, better-off, and educated men are more likely to be financially included than young, uneducated, and poor women. Education and living standards are thus very significant in explaining financial inclusion, which suggests that financial literacy matters to the choices individuals make with regard to saving income. The better-off individuals are, the more likely they will have a formal account, formal savings, and access to formal credit. According to 2017 Findex, only 32 percent of individuals in the lowest wealth quintile had a formal bank account, compared to 63 percent of those in the richest quintile. The differences are similar for formal savings and formal credit. Similarly, the more education Tanzanians have, the more likely they are to have access to major financial tools; for instance, all respondents who had a tertiary education had a formal bank account, compared to only 41 percent of those who had completed no more than primary education. HBS 2018 found significantly lower rates: only 1.4 percent of individuals in the poorest quintile had a savings or current account compared to 35 percent of those in the richest. 


\section{Implications for Policy}

Tis report provides a comprehensive analysis of poverty in Tanzania. The analysis compares data from the 2017/18 HBS with those of the 2007 and the 2011/12 HBSs. It also incorporates information from other sources such as Waves 1 to 4 of the NPS, the 2006 and 2013 Enterprise Surveys, the 2013 CIP, the 2014/15 SBR, the rebased GDP statistics, the 2006 and 2014 ILFSs, the 2015/16 DHS, the 2017 Findex, the 2012 Population and Housing Census, and satellite data. Drawing on all these sources gives a truly comprehensive picture of poverty in Tanzania, addressing issues that could not be captured from a single source. The rich analysis illustrates the diverse, multisectoral nature of poverty and its dynamics-useful information for prioritizing poverty reduction strategies. The report identifies areas where concerted efforts by the government and other stakeholders would yield the highest payoffs for poverty reduction and more sustainable and inclusive development. The policy pointers that follow are focused on making growth more inclusive through continued development of human capital, furthering structural transformation, and promoting growth of labor-intensive firms and creation of more productive jobs.

Tanzania has solid fundamentals for combatting poverty. With its rich and diverse resources, strategic location, effective planning, and political will, Tanzania is well positioned to use a variety of policy tools to promote productive job creation and reduce poverty and inequality. Besides strategies to accelerate growth to transform Tanzania into a middle-income, semi-industrialized economy and to strengthen human capital, the government has initiated reforms to build up infrastructure, strengthen fiscal management, and improve the business environment. In recent years the government has also done a great deal to support the poorest Tanzanians: it has opened access to free primary education; increased incomes and reduced vulnerability through productive social safety nets; and expanded delivery and coverage of basic social and community services. Although these efforts have indeed helped to reduce poverty, they need to be intensified if they are to bring about sustained improvements in the lives of Tanzanians. 
Policy now needs to be directed to ending the vicious cycles of unequal opportunity and vulnerability and putting in place mutually reinforcing interventions to build capacity and foster better livelihoods. The basic commitments should be to improved service delivery and infrastructure for all; expanded employment opportunities and higher productivity; investments in human capital to help people develop the skills they need; and protection for the most vulnerable. The design of priority interventions should take into account the specifics of Tanzania's poverty.

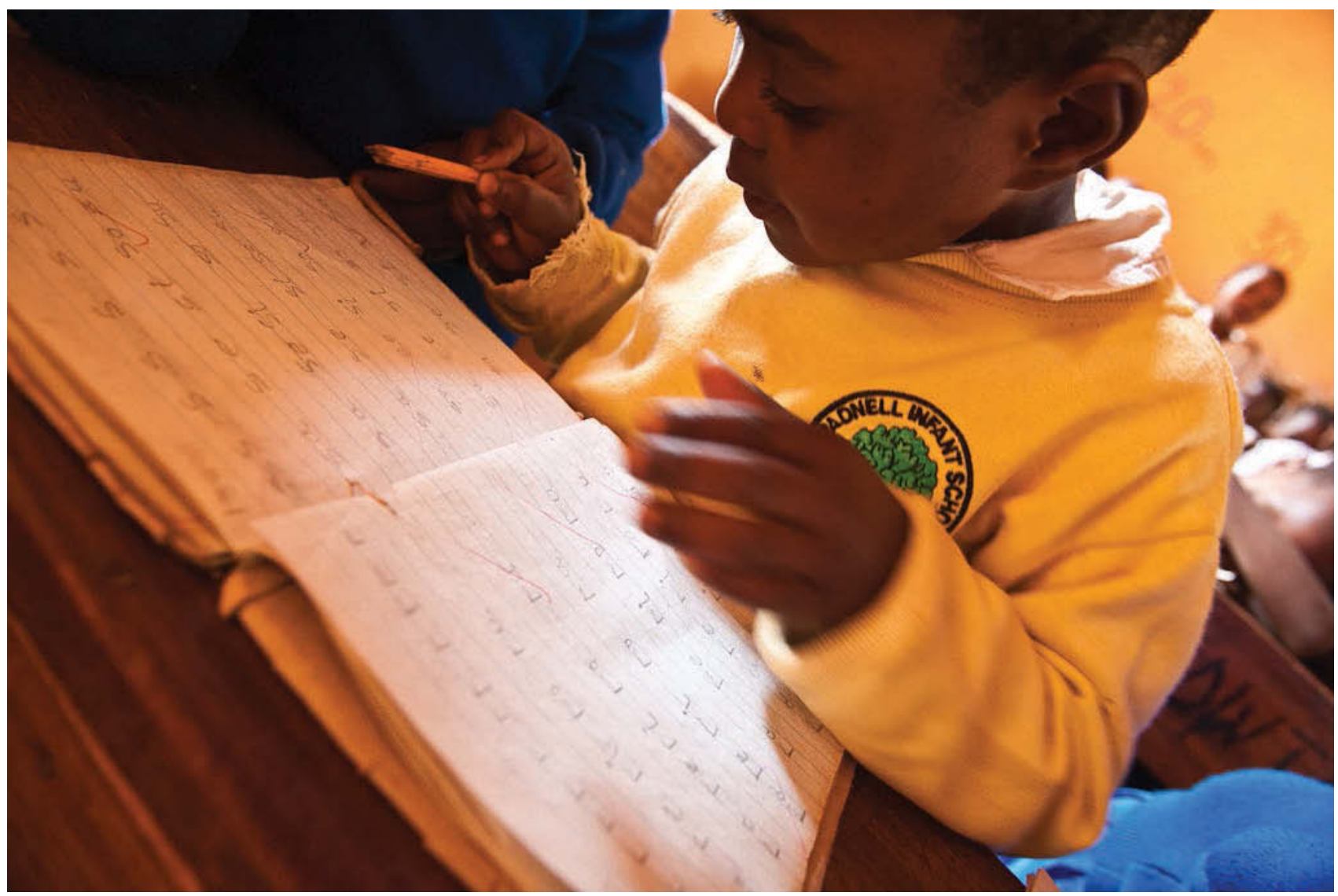




\section{Use a Well-Targeted Life-Cycle Approach to Enrich Human Capital}

nvest in human capital and increase skills to heighten productivity and incomes and sustainably reduce

poverty. Improvement in human capital is among the factors that helped ease poverty. However, the reduction in poverty has been quite slow compared to Tanzania's remarkable economic growth—which was driven by sectors that are not always open to the poor and mainly benefited those with higher education and more endowments.

Building human capital is critical to ensure more inclusive growth and faster poverty reduction. Because such investments are structural, they are likely to be long-term interventions. Meeting the goals will require a four-pronged reform strategy: (1) expand provision of early childhood development services to build the foundational capabilities,

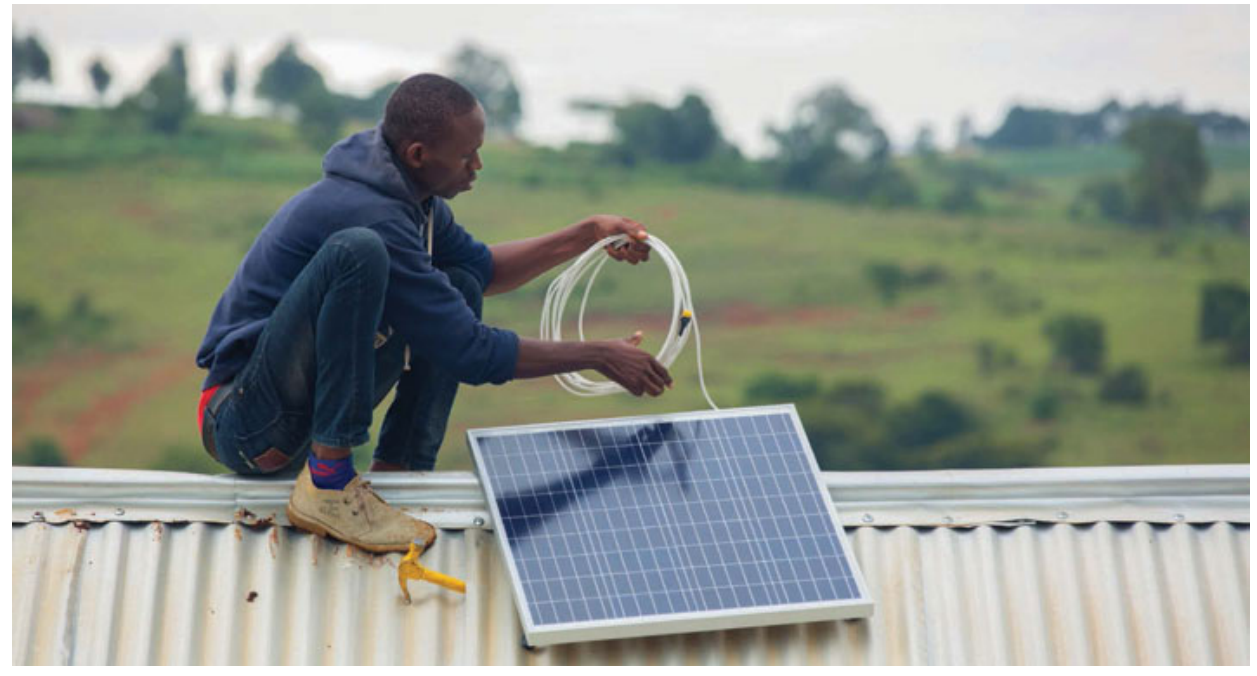
cognitive and noncognitive, of tomorrow's workers; (2) empower vulnerable families; (3) invest more in education and education quality; and (4) improve the capability of those new to the labor market and upgrade the skills of current workers. The first prong has a long-term agenda, but the second through fourth can be accomplished in the 
short to medium term. The reforms should be part of a cohesive and sequenced policy agenda guided by economic development needs, that address current and coming needs for skills. They should be complemented by interventions to improve the quality and accessibility of primary health care and social services so as to raise labor productivity and empower poor people. Evidence from the report points to the following priorities throughout the life cycle:

- By investing in their early years, move children to high-development trajectories. Poor children under five suffer from acute malnutrition, manifested by high stunting, particularly in rural areas. Deprivations not only in nutrition but also in such basic amenities as safe water and sanitation impair their current and future learning and development and will have long-lasting effects on their socioeconomic achievements. While some losses are irreversible, others can be partly mitigated by early stimulation. Preventing stunting for new generations is possible with a sound combination of targeted social services (nutrition, income support), community monitoring, and parental education. An additional priority for early childhood development is advancing government efforts related to maternal and infant health. Essential interventions are expanding access to health care; universal provision of safe water and adequate sanitation; and mainstreaming health and nutrition interventions. Investments in the supply and quality of both preschool and basic education will also help to build cognitive skills in early childhood, enhance abilities and motivation for learning, and sustain learning throughout schooling and beyond.

- Draft and apply a policy to empower families that have a large number of dependents and strengthen the resilience of vulnerable populations. Poverty is significantly higher among households with a large number of children and dependents. Improving human capital in these households could eventually lower the number of children and dependents. The policy should incorporate factors that promote the education of girls and the participation of women in the labor force, both of which have implications for fertility and poverty. The PSSN program has had an impact in strengthening resiliency and reducing poverty; without the program both the proportion and number of poor people would have been much higher. However, only 14 percent of poor households and 9 percent of total households benefit from PSSN. Today, several years since the program was designed, targeting of the cash transfer program needs to be revisited, but a mechanism should also be put in place to strengthen the resilience of those who graduated from the program to ensure that they do not fall back into poverty.

- Provide universal access to education beyond the primary level, particularly for girls. Currently, 18 percent of Tanzanians have no education and of those with some schooling, 60 percent did not go beyond primary school; and the rates for women are 23 and 58 percent. Enrollment in lower secondary and beyond is very low generally and strikingly so among poor families. This suggests that deficiencies in education will perpetuate over time. Because those with secondary or higher education were better able to benefit from the returns of 
economic growth and escape poverty, a policy that expands access to secondary and higher education could ultimately open up job opportunities in more productive sectors. Policies need to give special attention to expanding access to higher education for girls, particularly girls in rural areas and in poor families.

- Build the capacity of current workers and bridge skills gaps through technical training. In expanding access to higher education, it is essential that technical and vocational tracks provide graduates with the solid general skills the labor market demands. Technical and vocational schooling could also be a fast way to train mid-level skilled workers for the immediate needs of the labor market but might not equip graduates with a solid foundation of general skills that allow them to adapt as labor market requirements change. It is also probable that young graduates from the general track who do not enter tertiary education lack many job-relevant skills. It is important that all tracks provide the right skills mix and that tracks are permeable enough to ensure that graduates have a range of paths for continuing to acquire skills. Improving the access and relevance of technical and pre-employment training is the most direct way to build the skills of the current workforce. Better coordination with private employers is necessary to design market-relevant curricula and course offerings and to provide financial and technical support that better responds to the needs of growing sectors of the economy. It is also important to incorporate gender equity into development programs and projects to ensure that all citizens have equitable access to human development efforts. This could open up job opportunities in sectors where women do not traditionally work and help to empower them. 


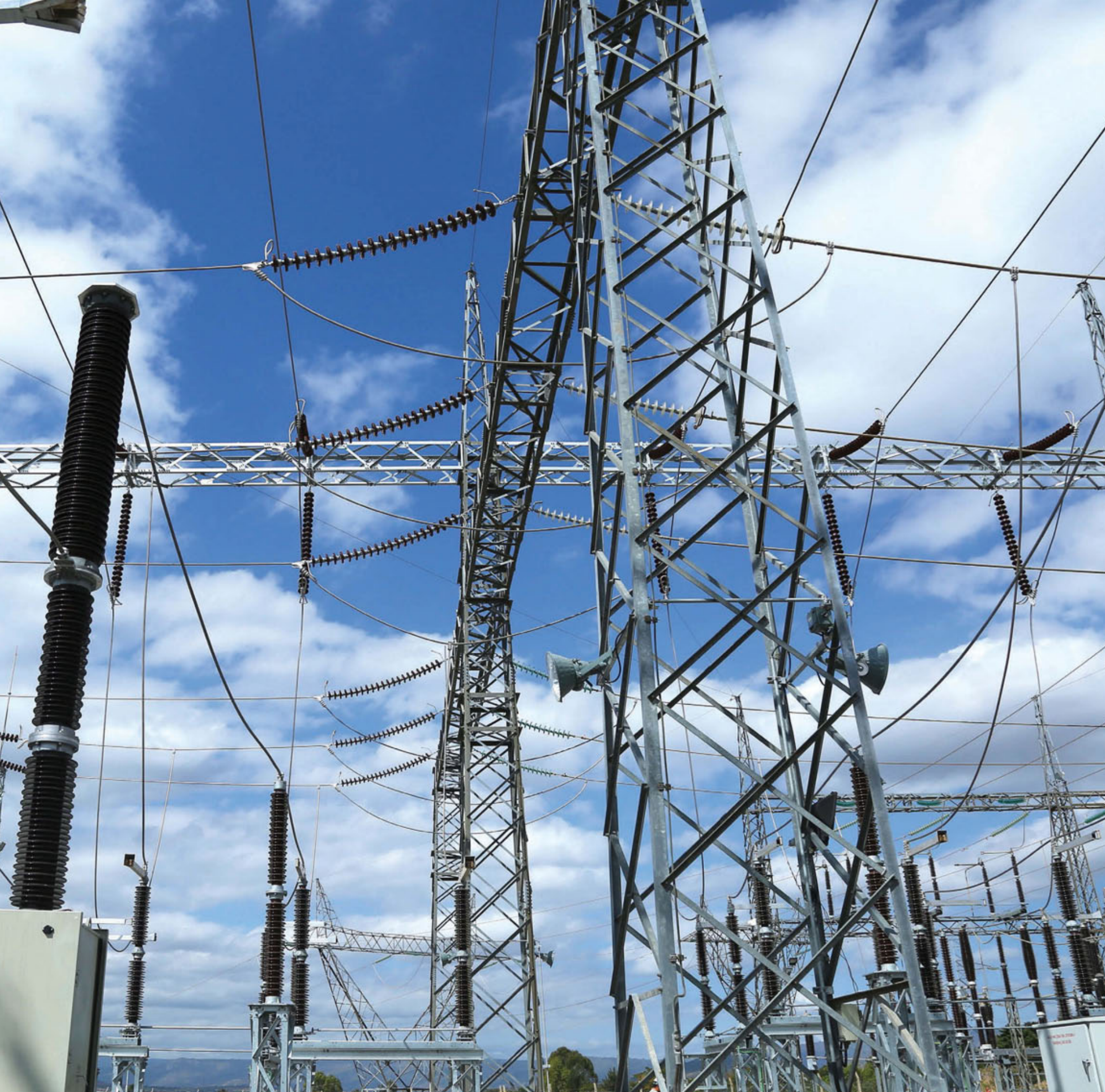




\section{Take Advantage of the Momentum Created by Investments in Basic Services to Expand Service Delivery}

nvestment in social and community services could make these services more accessible in rural areas, which would maximize their impact on poverty reduction. Access to electricity, safe water, sanitation, and roads has helped reduce poverty, but services in rural areas and for the poor are still inadequate. Access to electricity is still low, but in rural areas use of solar energy as a source of lighting is expanding. Access to safe water has doubled in urban areas but there has been limited changes in rural areas, which also suffer from minimal change in access to improved sanitation. Most rural roads are still rudimentary. It is therefore necessary to:

- Increase coverage and access to basic services. For instance, expand the electricity grid to reach more rural households; promote solar energy as a source of lighting; expand the water system to improve access to safe drinking water and bring water closer to users to minimize the time and distance required to access it; and expand sanitation systems.

- Expand the road network and improve the quality of roads and their links to better link rural farmers to urban markets. Access to roads has been identified as crucial if rural incomes are to grow. Better rural roads will reduce the costs of moving agricultural products and promote agricultural marketing and commercialization. 


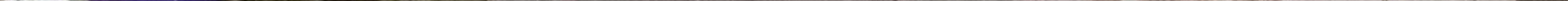




\section{Accelerate Creation of Productive Jobs by Boosting the Benefits of Structural Transformation and Promoting Opportunities for Small Firms to Grow}

anzania's economy is transforming, but too slowly. The decrease in agriculture's contribution to GDP and the shift of labor from agriculture to services and industry suggests that the structure of the economy is being transformed, but the large productivity gaps between sectors suggest that faster transformation would provide significant productivity gains. Skills shortages are a formidable barrier to transformation, but so are other factors, such as the small size of Tanzanian firms and the difficulty they have in surviving and growing; the prevalence of informality; the lack of productive capacity; their limited access to financial resources and technology; and the general low value-added of small firms. Micro and small enterprises need to be empowered to further structural transformation and increase creation of productive jobs. Because agriculture remains the mainstay of the vast majority of the poor, it needs to be made more productive. The following could help address these issues:

- Boost the productivity of agriculture. Despite the continuing transition of agricultural workers to services and industry, the livelihoods of a significant number of Tanzanians still depend on agriculture. Among efforts to make agriculture more productive that should continue are supplying farmers with the inputs necessary to increase fertilization and improve irrigation and soil management; and providing credit, transport, and marketing facilities. Efforts should also 
be directed to supporting a transition to cash crops and commercial agriculture, where productivity and economic returns are higher.

- Build the capacity of micro and small enterprises to survive and grow in order to support income growth and creation of better jobs. For some poor workers, self-employment is the most viable way out of unemployment and poverty. Targeted interventions to improve returns to self-employment by, e.g., facilitating access to productive assets, frequent and sustained coaching, pre- and post-business creation advisory services for entrepreneurs, and specific social support measures could help push up their profitability and economic returns.

- Remove barriers to accessing finance. If private businesses are to grow and poor households to generate income to break the cycle of poverty, both need external financing.

- Promote financial literacy. Besides expanding access of the poor and microenterprises to credit, inclusion may depend on empowering them by educating them on the best available financial options, how to save for life events, and how to use insurance or similar products to prepare for the unexpected.

- Improve the general business environment, which is crucial to private sector growth and job creation. Since job creation is the most immediate avenue to promoting pro-poor growth, and the private sector employs most of Tanzania's workforce, accelerating growth and promoting shared prosperity will depend on significant improvements in the national business environment.

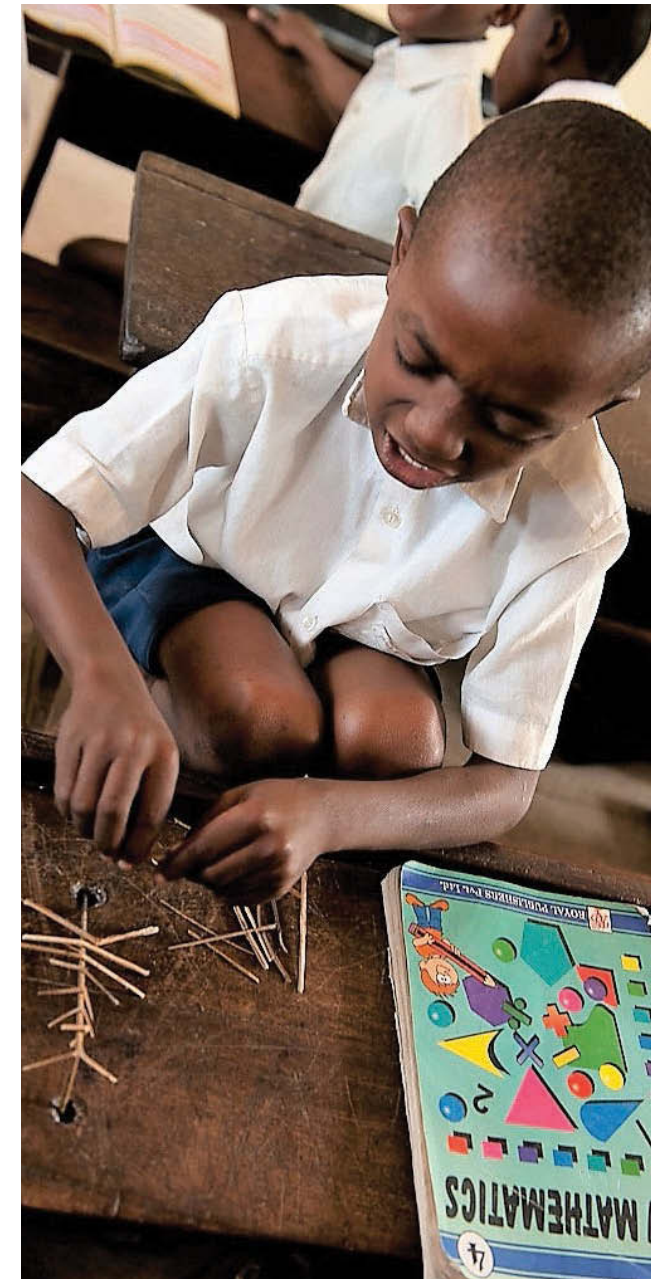




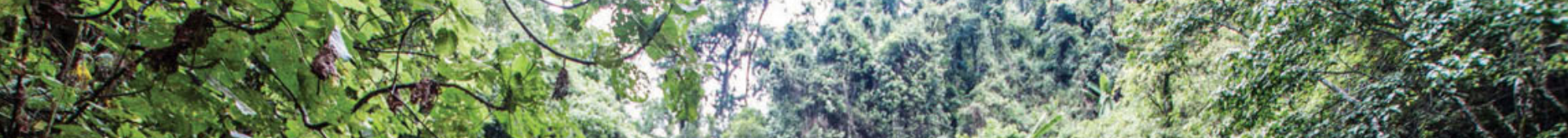

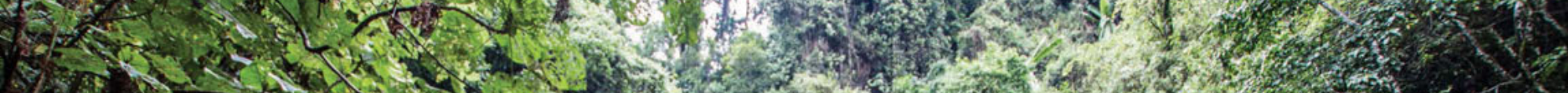

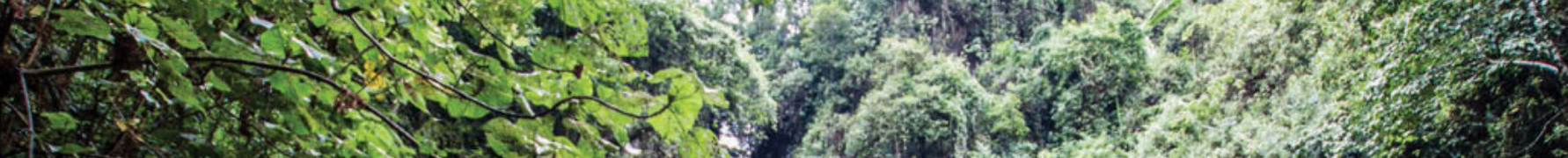

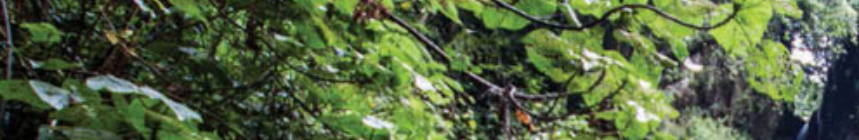
2., $3.20 \times 1 \times$

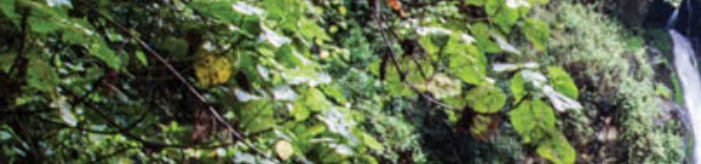
$5+1,112$ 2. $+2 .+1+2$

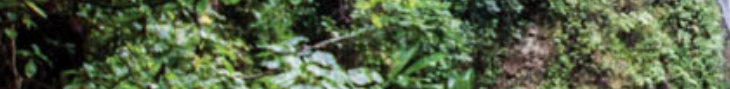
s.

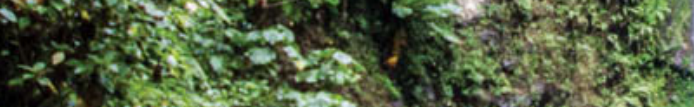
$-7,2$ wes?

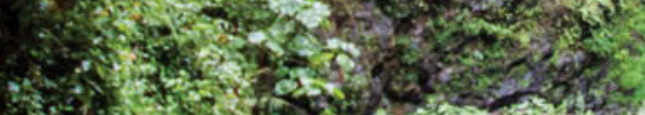

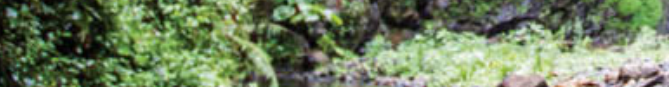
3.5.

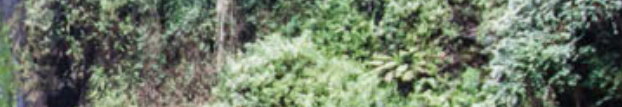

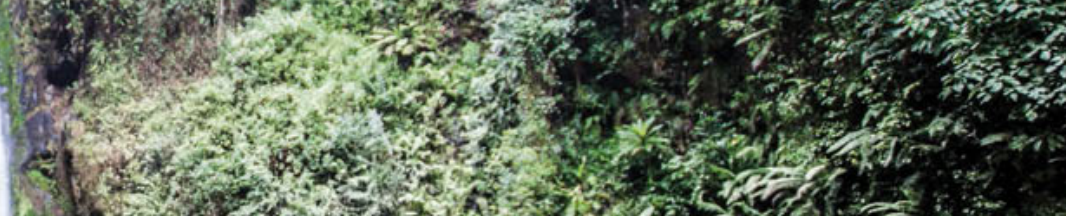
(t) 35 (3)

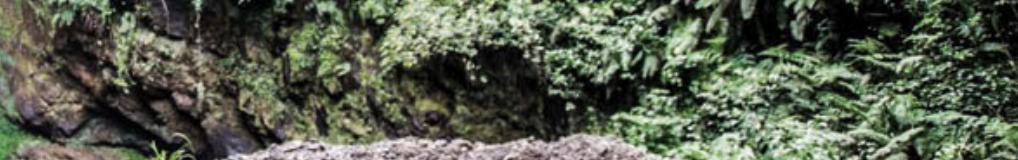
Sis.

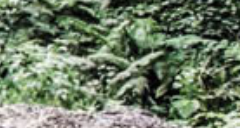

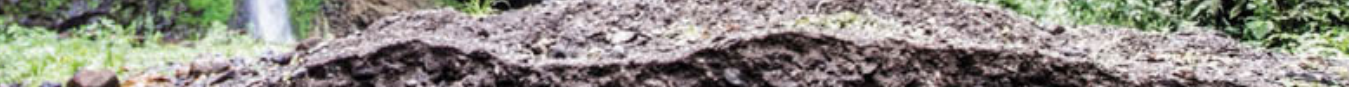

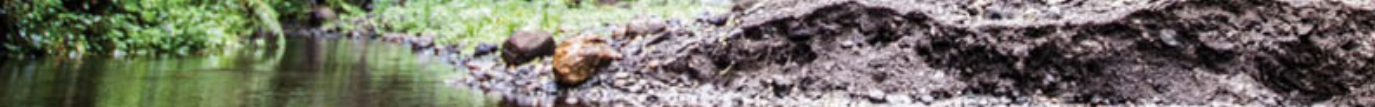

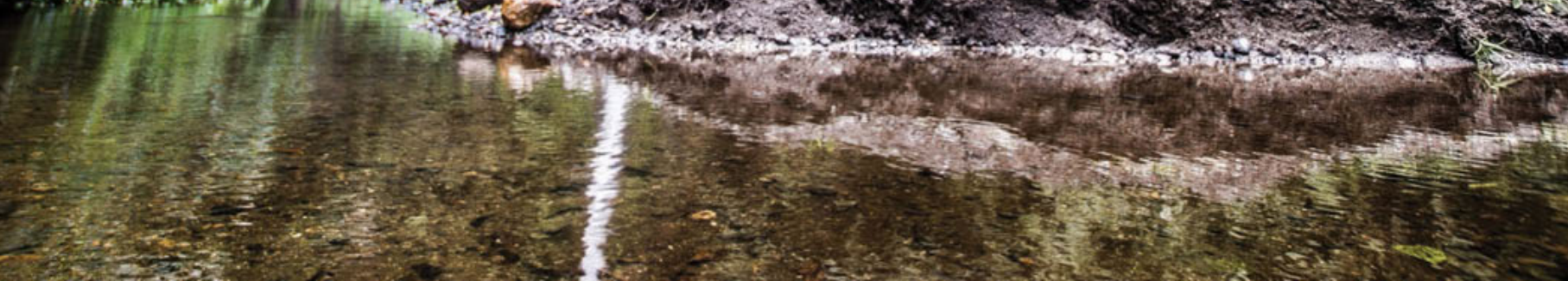

(4) WORLD BANK GROUP 